\title{
De cláusulas y modulaciones. Sobre un aparente "defecto" en la obra de José de Campderrós (ca. 1742-1811)
}

\author{
On cadences and modulations. \\ On an apparent "defect" in the work \\ of José de Campderrós (ca. 1742-1811)
}

\author{
por \\ Alejandro Vera Aguilera \\ Instituto de Música. Pontificia Universidad Católica de Chile, Chile. \\ averaa@uc.cl
}

El presente trabajo estudia un aparente "defecto" que se desprende de la comparación entre la música de José de Campderrós, compositor catalán activo en Chile hacia 1800, y los "grandes clásicos". Según se explica en la introducción, se trata de su tendencia a incluir secciones con muy escasas modulaciones o sin modulación ni inflexión alguna a otra tonalidad, algo que ya fuera criticado por el compositor Jorge Urrutia Blondel en 1941. El apartado 1 demuestra que dicha tendencia es efectiva en una buena parte de la música de Campderrós, lo que contrasta marcadamente con la práctica generalizada de los compositores tradicionalmente conocidos como "galantes" y "clásicos", para los que la modulación constituye un recurso esencial del que solo prescinden muy excepcionalmente. En el apartado 2 se analizan con mayor detalle algunas obras de Campderrós, prestándose una atención especial a las modulaciones, inflexiones y su función. En el tercero, se compara a dichas obras con la teoría española del siglo XVIII, con la hipótesis de que su renuencia a incorporar de lleno los procedimientos modulatorios y sus indicaciones, a veces indirectas, sobre los mismos, debieron influir en la práctica compositiva del músico catalán y pueden ayudarnos a comprender mejor su forma de modular. Para concluir, se propone que este aparente "defecto" responde más bien a la aplicación de convenciones diferentes a las del repertorio galante y clásico, al tiempo que refleja la confluencia entre una teoría española tradicional, todavía apegada al lenguaje modal, y una práctica moderna, de carácter tonal. Además, se plantea que este tipo de aproximación a la música de la época podría contribuir, en futuros trabajos, a iluminar la obra de otros compositores de la América colonial.

Palabras clave: Música en la América colonial, Catedral de Santiago de Chile, José de Campderrós, Teoría española del siglo XVIII, Modulación, Cláusulas, Modalidad, Tonalidad.

The present article studies what appears to be a "defect" that arises from the comparison between the music of José de Campderrós - a Catalan composer active in Chile around 1800- and the "great classics" of his time. As explained in the Introduction, such "defect" is his frequent tendency to include sections with very few modulations or even without any modulation or tonizication, a formal trait that the composer and theorist Jorge Urrutia Blondel criticized in 1941. The first section demonstrates that this assertion is valid for many of Campderrós' works, which contrasts sharply with the widespread practice in composers traditionally known as "galants" and "classicals", for whom 
modulation constitutes an essential resource that is only exceptionally dispensed with. The second section analyzes in more depth some of Campderrós's pieces, drawing particular attention to modulations, tonicizations, and their function. The third, compares these pieces with the Spanish theory of the 18th century, with the hypothesis that its reluctance to fully incorporate the modulatory procedures and its -frequently indirect-indications regarding them should have a powerful influence on Campderrós' compositional practice and can contribute to an understanding of its manner of modulating. To conclude, this article proposes that his apparent "defect" actually responds to the application of conventions different from those of the galant and classical repertoire, reflecting, at the same time, the confluence between a traditional Spanish theory, still attached to modal language, and modern practice of a tonal nature. Besides, it suggests that this type of approach to the music of the time may contribute, in future studies, to illuminate the work of other composers of colonial Latin America.

Keywords: Music in Colonial Latin America, Santiago de Chile Cathedral, José de Campderrós, Spanish Theory in the 18th Century, Modulation, Cadences, Modality, Tonality.

\section{INTRODUCCIÓN ${ }^{1}$}

Como es sabido, José de Campderrós fue un compositor catalán que trabajó como maestro de capilla en la catedral de Santiago de Chile en torno a 1800 y cuya obra se ha conservado íntegramente en dicha institución. Aunque su biografía aún presente importantes vacíos, se ha documentado que era natural de Barcelona e hijo legítimo de Martín Campderrós y Magdalena Pascual (Pereira Salas 1941: 59; Claro Valdés 1977a: 129; cf. Velásquez Cantín 2003: 18-20). En 1774 zarpó de Cádiz a Lima en el navío San José, alias El Aquiles, en calidad de comerciante. Según su expediente de pasajero, encontrado por Claro, era "blanco, cerrado de barba" y tenía 32 años, lo que sitúa su nacimiento hacia 1742 (Claro Valdés 1977a: 124).

Desafortunadamente no se han encontrado noticias acerca de sus actividades en la sede virreinal. Podría referir a Campderrós una carta publicada en 1792 por el músico peruano Toribio del Campo y Pando, en la que afirma que "Un tal cual instrumentario Músico que ha pasado a este reino bajo el título de comerciante, no ha tenido la bondad de querer comunicar las reglas del manejo de su instrumento" (citado por Estenssoro 1989: $75)^{2}$. Pero también es posible que se trate de otra persona, pues la llegada de músicos adscritos a otros oficios no era algo tan excepcional en Hispanoamérica (cf. Gembero Ustárroz 2007: 30-32).

En 1793 Campderrós ocupaba ya la maestría de capilla de la catedral de Santiago, pues así consta en las portadas de algunas de sus obras ${ }^{3}$. Tanto Pereira Salas como Claro señalan que su nombramiento se realizó por concurso (Pereira Salas 1941: 59; Claro Valdés

1 Este artículo fue escrito en el marco del proyecto FONDECYT 1170071, en el que también participa el musicólogo David Andrés Fernández como coinvestigador. Agradezco a Macarena Aguayo, ayudante de investigación, y Paul Feller, tesista del proyecto, su colaboración en la recopilación de material para este artículo, según se precisa más adelante. Agradezco, así mismo, a los evaluadores de las versiones anteriores, cuyas recomendaciones han contribuido a mejorar el texto original. Una versión preliminar de este trabajo figura como apartado del capítulo 5 de mi libro El dulce reato de la música. La vida musical en Santiago de Chile durante el período colonial (La Habana: Casa de las Américas, 2020). Así mismo, presenté una versión resumida en la segunda de las cuatro conferencias que ofrecí en el CENIDIM de México en el marco de la Cátedra Jesús C. Romero, 2018, disponible en https://www.youtube.com/watch?v=AgqXPqfrJxE\&t=1465s [acceso: 4 de agosto de 2019].

2 En la transcripción de textos de la época he modernizado todo lo que no tiene valor fonético, incluso cuando se trata de transcripciones realizadas por otros autores.

3 Véase Archivo de la Catedral de Santiago (en adelante ACS), Fondo de Música (en adelante FM), carpetas 21, 22, 137 y 466. Cf. el catálogo de Claro Valdés 1974a. 
y Urrutia Blondel 1973: 75; Claro Valdés 1977a: 127), pero no ofrecen evidencia alguna que respalde esta afirmación.

A comienzos de 1797 se casó con María de las Nieves Machado (Claro Valdés 1977a: 129), con quien otorgó ese mismo año un testamento mutuo. La firma de Campderrós, inscrita al pie del documento, confirma que se trata de la misma persona que en 1774 había zarpado con destino a Lima (Pereira Salas 1941: 59; Claro Valdés 1977a: 125).

El 15 de noviembre de 1806 examinó musicalmente a la clarisa Manuela de la Cruz Infante para comprobar si se hallaba apta para ingresar como cantora en el Monasterio de La Victoria. No se han conservado otros informes similares firmados por él, pero es probable que los hubiese, ya que era frecuente que algunas religiosas buscasen rebajar o eximirse de la dote por medio de un oficio musical (Vera 2010a: 26-43).

No tenemos más datos biográficos acerca de Campderrós hasta su entierro, que tuvo lugar el 26 de marzo de 1811 en la catedral de Santiago (Vera 2005: 25). A fines del año siguiente fue reemplazado por José Antonio González, quien se había desempeñado antes como organista e iba a ocupar la maestría de capilla por casi tres décadas (Claro Valdés 1979: 11-14).

Respecto de su música, los géneros que cultivó eran los propios de cualquier maestro de capilla: por un lado, repertorio latino para las celebraciones del año litúrgico (entre otros, misas, oficios de difuntos, lamentaciones para la Semana Santa y salmos de vísperas); por otro, villancicos a diversas advocaciones (Navidad, la Virgen María, los santos, el Sagrado Corazón, etc.) y un trisagio a la Santísima Trinidad, todos ellos en lengua romance.

El hecho de que su música continuase reutilizándose durante todo el siglo XIX pone de manifiesto la importancia que tenía para la institución (Cabrera 2010: 42-61). Pese a ello, los juicios respecto de la misma no siempre han sido tan positivos como podría haberse esperado. El más antiguo se debe al compositor y teórico Jorge Urrutia Blondel y fue concebido originalmente para una antología de la música colonial que planeaba publicar con Eugenio Pereira Salas (cf. Pereira Salas 1941: 55). Aunque esta publicación no llegó a concretarse, este último decidió citar el testimonio de su colega en Los orígenes del arte musical en Chile (1941). En síntesis, Urrutia consideraba al compositor catalán un fiel representante del "clasicismo armónico" de finales del siglo XVIII y reconocía su "uso muy razonable" de los violines y el bajo cifrado. Sin embargo, sus figuraciones le parecían "poco interesantes" y su "orquestación muy elemental". Así mismo, cuestionaba su nulo empleo de las posibilidades técnicas y expresivas de los instrumentos de viento y, sobre todo, su pobreza armónica en comparación con los "grandes clásicos":

Fuera de que sus ritmos y melodías no son dúctiles recurre exclusivamente al uso de los acordes principales, al de Séptima de Dominante. Nunca utiliza los acordes paralelos, las apoyaturas, retardos y las funciones transitorias tan bien explotadas por los clásicos. La monotonía es solo interrumpida por algunas modulaciones de tonos cercanos (citado por Pereira Salas 1941: 60).

Urrutia observó, además, una "ausencia de contrapunto" y propuso que podía deberse a que Campderrós lo consideraba anticuado o a que "no llegó a dominar con seguridad tan importante recurso y medio de expresión musical..." (Ibídem).

Pereira Salas, quien no tenía los conocimientos técnicos suficientes para confirmar o rebatir lo dicho, dio por válidos los juicios de Urrutia en términos generales. Sin embargo, señaló a renglón seguido que "A pesar de todos estos defectos técnicos el ascendiente de Campderrós sobre la música religiosa fue absoluto" (Pereira Salas 1941: 38, 60).

En épocas posteriores, la música de Campderrós fue objeto de diversas valoraciones. Tras el estreno de su "Misa en sol mayor" en 1971, por la orquesta de cámara y el coro de 
la Universidad Católica dirigidos por Fernando Rosas ${ }^{4}$, el crítico musical Federico Heinlein afirmó haber hallado "pasajes inspirados", como "el cromático Cruxifixus", y destacó la "sucesión de tonalidades hábilmente planeada". Aun así, señaló la existencia de "pequeñas desmañas de redacción” (Heinlein 1971: 51), sin dar detalles al respecto5.

Poco después, el musicólogo Samuel Claro Valdés afirmaría que Campderrós era un "compositor de oficio", de estilo preclásico y "diestro en el manejo de coros y orquesta". Además, hizo notar que cultivaba el villancico español y le atribuyó el uso de procedimientos retóricos (Claro Valdés y Urrutia Blondel 1973: 75; Claro Valdés 1974b: xxv; Claro Valdés 1977b: 244; Claro Valdés 1977a: 133).

En una época más reciente, Rebeca Velásquez Cantín ha cuestionado los juicios de Urrutia por haber analizado una muestra no precisada -aunque al parecer muy reducidade obras e ignorar el contexto para el que fueron escritas (Velásquez Cantín 2003: 22-23; cf. Velásquez Cantín, 2001: 28). Su valoración de la música de Campderrós es más positiva, pues señala su buen manejo de las partes vocales y las cuerdas (Velásquez Cantín 2003: 68). Aun así, reconoce que las maderas exhiben un tratamiento "muy sencillo" y que su manejo de la armonía es "rudimentario" e incluso "inocente". A su juicio, esto último podría deberse al "peso de siglos de modalidad", hipótesis que no desarrolla, pero que en el contexto de este trabajo resulta de especial interés, como luego se verá (Ibídem, 69).

De manera que, sin perjuicio de sus diferencias, los dichos de Velásquez Cantín son coincidentes con los de Urrutia en lo que concierne al dominio, aparentemente escaso, de ciertos recursos armónicos. En consecuencia, me interesa reevaluar si este último pudo tener algo de razón al señalar la escasez de modulaciones o funciones transitorias y, en caso de ser así, buscar explicaciones que vayan más allá de la posible incompetencia técnica de Campderrós para abordar el pensamiento y la cultura musical de su tiempo. De esta forma, es posible que logremos no solo comprender mejor un corpus de obras específico, sino también proporcionar ideas o herramientas que puedan resultar útiles para estudiar, en el futuro, otras figuras y repertorios de la época.

\section{EL JUICIO DE URRUTIA COMO PROBLEMA DE INVESTIGACIÓN}

A objeto de verificar si la escasez de modulaciones y funciones transitorias señalada por Urrutia es o no un rasgo efectivo en la música de Campderrós, me dediqué a listar el número de modulaciones e inflexiones ${ }^{6}$ en treinta de las casi setenta obras de su autoría que se conservan en el Archivo de la Catedral de Santiago ${ }^{7}$. Como se ve en la Tabla 1,

4 La pieza fue transcrita para la ocasión por el musicólogo Samuel Claro Valdés e incluida al año siguiente en un disco (Rosas 1972). Para esta grabación Claro prefirió quitar algunas partes del Gloria y el Credo, con el fin de que la duración no excediera una cara de un disco LP. Fue esta transcripción parcial la que finalmente publicó en su Antología (Claro Valdés 1974b: cv, 175-212).

5 Aunque esta es la única crítica al concierto que hemos hallado, este fue anunciado en $L a$ Prensa (28 de agosto, 1971), p. 2; El Mercurio (5 de septiembre, 1971), p. 11; y La Tercera de la Hora (9 de septiembre, 1971), p. 11. Otros anuncios se hallan en El Mercurio (30 de agosto, 1971), p. 23 y 5 de septiembre, 1971, p. 11; y La Prensa (28 de agosto, 1971), p. 2, ambos conservados en el ACS, cuyo conocimiento debo a la gentileza de la archivera, Carmen Pizarro. Cf. La Tercera de la Hora, 9 de septiembre, 1971, p. 11; y El Mercurio, 9 de septiembre, 1971, p. 22. Agradezco a Macarena Aguayo su ayuda en la revisión de la prensa chilena de 1971.

6 Empleo este término -en lugar de los anglicismos "tonización" o "tonicalización"- para referir a un traslado por muy breve tiempo a otra tonalidad.

7 Esta cifra es inferior a la que indican Claro Valdés 1977a: 132 y Velásquez Cantín 2003: 34 (84 y 85 , respectivamente). La diferencia se explica porque existen correspondencias entre obras no identificadas por dichos autores. 
trece de ellas incluyen al menos una sección en la que solo hay una inflexión hacia otra tonalidad $^{8}$, y otras nueve -casi un tercio del material revisado-, que contienen una o más secciones sin modulación ni inflexión alguna ${ }^{9}$. Podría pensarse que esto se explica por su brevedad, pero la segunda sección del villancico "Amados pastores" (Tabla 1, $\mathrm{N}^{\circ}$ 3) y el Gloria de la "Misa a 3" (Tabla 1, No 23) tienen cerca de treinta compases, espacio más que suficiente para moverse a otra tonalidad. Tampoco parece haber una correspondencia con algún género particular, pues las secciones de este tipo se encuentran en piezas diversas, tanto latinas como vernáculas: una lamentación ( $\left.\mathrm{N}^{\circ} 2\right)$, salmos de vísperas ( $\left.\mathrm{N}^{\text {os. }} 4-5,20\right)$, villancicos ( $\left.\mathrm{N}^{\text {os. }} 1,27\right)$, un magníficat $\left(\mathrm{N}^{\circ} 21\right)$, una misa $\left(\mathrm{N}^{\circ} 23\right)$ y el canto introductorio "Domine ad adjuvandum" ( $\left.\mathrm{N}^{\circ} 14\right)$.

Ahora bien, como la escasez es un concepto relativo, la pregunta siguiente sería cuál era el corpus de obras con el que Urrutia estaba comparando la música de Campderrós. Aunque resulte difícil responder con certeza, parece probable que al hablar de "los clásicos" aludiese a los compositores más conocidos de fines del siglo XVIII, especialmente Joseph Haydn y W. A. Mozart. De hecho, en uno de sus primeros escritos, relativo a Beethoven, Urrutia menciona repetidamente a Haydn y Mozart como sus principales predecesores (Urrutia Blondel 1927: 21-24), y en otro muy posterior alude a Mozart y "otros grandes clásicos" (Urrutia Blondel 1971: 9).

La presencia de secciones como las señaladas en la obra de Haydn o Mozart parece algo improbable, porque, como veremos en el siguiente apartado, el lenguaje tonal se desarrolló a partir de una ampliación de la forma binaria que, aun en su forma más elemental, implicaba un tránsito entre la tonalidad principal y otra secundaria -normalmente la dominante o relativa mayor-. Pero la única forma de comprobarlo sería mediante una revisión exhaustiva de sus composiciones, algo que excedería con creces las dimensiones y el propósito de este trabajo. Aun así, he querido cotejar una muestra de su música sacra, que incluye diecisiete piezas de Haydn ${ }^{10}$ y cincuenta y una de Mozart ${ }^{11}$. Además, he revisado obras de sus contemporáneos Luigi Boccherini ${ }^{12}$ y Antonio Salieri ${ }^{13}$. De estas ochenta y tres obras revisadas, solo una sección -el Sanctus de la misa breve en do mayor K.220/196b de Mozart- se mantiene firmemente atada a la tonalidad principal.

8 Tabla 1, Nos. 5, 13-14, 16-18, 20-21, 23-24, 26-27, 30.

9 Tabla 1, Nos. 2-5, 14, 20-21, 23, 27.

10 Hob.XXII: 5-14 (misas) y Hob.XXa:1; Hob.XXI:2; Hob.XXIIIa:1; Hob.XXIIIb:2; Hob.XXIIIc:1; Hob.XXIIIc:2; Hob.XX:2 (otras piezas sacras). Es preciso señalar que esta lista incluye la misa "Sancti Joannis de Deo" (Hob.XXII:7), la que, pese a su brevedad, incluye modulaciones en todas sus secciones. He tomado como punto de partida la base de datos Petrucci Music Library, disponible en https://imslp. org/wiki/Main_Page, así como el sitio web de Europeana, disponible en https://www.europeana.eu/ portal/en. Salvo que se indique lo contrario, para la identificación de las obras remito a las entradas de los compositores en el New Grove. Agradezco a Paul Feller su ayuda en esta revisión.

11 K.49/47d, K.65/61a, K.66, K.139/47a, K.140/Anh.C1.12, K.167, K.192/186f, K.194/186h, K.220/196b, K.258, K.259, K.275/272b, K.317, K.337 y K.427/417a (misas, algunas de ellas breves); y K.33, K.34, K.42/35a, K.44/73u, K.47, K.72/74f, K.85/73s, K.86/73v, K.89/73k, K.91/186i, K.108/74d, K.109/74e, K.117/66a, K.125, K.127, K.141/66b, K.142/Anh.C3.04, K.143/73a, K.165/158a, K.193/186g, K.195/186d, K.197/Anh.C3.05, K.198/Anh.C3.08, K.222/205a, K.243, K.260/248a, K.276/321b, K.277/272a, K.322/296a, K.341/368a, K.343/336c, K.321, K.339, K.618, K.626 y K.Anh.15/323 (otras obras religiosas).

12 G. 529, G. 530, G. 531, G. 532, G 533, G 534, G 539.

13 Misa en Re mayor (1788), Te Deum (1790), "De profundis" en sol menor (1805), "Veni Sancte Spiritus" (1805), "Lauda Jerusalem" (1815), "Réquiem" en do menor (1804), "Salve Regina" en si bemol mayor (s/f) y "Magnificat" en do mayor" (s/f). Cf. Hettrick 1986: 232-234. 
Descartada la relación con los clásicos, podría buscarse otra explicación en la posible influencia del estilo galante -hemos visto que Claro consideraba a Campderrós un compositor "preclásico"-. Por esta razón, he querido revisar también una muestra de cuarenta obras o colecciones de compositores tradicionalmente considerados como representantes de este estilo: Carl Philipp Emanuel Bach ${ }^{14}$, Johann Christian Bach ${ }^{15}$, Franz Xaver Richter ${ }^{16}$, Johann Stamitz ${ }^{17}$ y Baldassare Galuppi ${ }^{18}$. El resultado no es muy diferente, pues solo una breve canción sacra de las veinticinco que C. P. E. Bach publicó en 1771 carece de modulaciones e inflexiones (Bach 1771: 21), hecho que podría explicarse por su carácter tradicional.

Aun considerando las limitaciones de esta revisión ${ }^{19}$, resulta suficiente para confirmar que la modulación constituía, para los compositores galantes y clásicos, un recurso esencial del que solo prescindían muy esporádicamente. Por tanto, Urrutia tenía razón en el hecho formal que constató -las modulaciones de Campderrós son escasas en comparación con las que normalmente efectuaban "los clásicos"-, pero no necesariamente en la explicación que propuso -que esto podía deberse a la incapacidad del compositor-. Con esto no quiero decir que las posibles carencias musicales de Campderrós deban descartarse a priori, sino que puede resultar más productivo transformar el juicio de Urrutia en un problema de investigación, lo que implica buscar explicaciones que sitúen su música en un contexto más amplio.

En este sentido, hay al menos otras dos explicaciones posibles, no excluyentes entre sí: que la mayor estabilidad tonal responda a motivos de orden litúrgico; o que dé cuenta de un lenguaje musical diferente a los que acostumbramos designar como "galante" y "clásico". La primera implicaría prestar atención a la inserción del repertorio en la liturgia; la segunda, situar determinados procedimientos técnicos y compositivos en el marco más amplio del pensamiento y la teoría musical de la época. Ambas apuntan al contexto histórico y cultural, pero hacen énfasis en dimensiones diferentes del mismo.

En lo que resta de este artículo exploro la segunda alternativa. Mi hipótesis es que algunos elementos para comprender el uso que Campderrós hace de las modulaciones pueden hallarse en la teoría española del siglo XVIII, que nuestro compositor debió conocer y utilizar. En este sentido, dicho uso no sería azaroso, ni tampoco el reflejo de un sello personal, sino que respondería a convenciones diferentes a las que predominaban en el repertorio galante y clásico, pero que se hallaban, al menos en parte, normadas por los tratadistas españoles de la época.

\section{ANÁLISIS DE ALGUNAS OBRAS}

Antes de revisar la teoría española del siglo XVIII, me parece necesario analizar con mayor detalle algunas de las obras listadas en la Tabla 1. Por limitaciones de espacio propias de un artículo de revista, me concentraré en cuatro piezas, escogidas de las nueve que incluyen

14 H.686, H.696, H.733, H.749, H.772, H.775, H.777, H.778, H.780, H.800, H.802, H.807 у H. 825.

15 W E2, W E4, W E5, W E10, W E12, W E14, W E16, W E17, W E22, W E24.

16 "Magnificat" en do mayor; Réquiem en mi bemol mayor, Te Deum en re mayor.

17 Misa en re mayor a cuatro voces.

18 "Laetatus sum" en la mayor; "Lauda anima mea" en sol mayor; "Lauda Jerusalem" en do mayor; "Laudate Dominum quoniam bonum est" en la menor; "Laudate pueri" en fa mayor; Misa en do mayor (BurG I/2); "Sinfonía" en re mayor; Sonatas en do menor, la mayor, fa mayor y sol menor para teclado; Sonata en re mayor para cello y teclado; y Tedeum (BurG IV/2).

19 Su carácter no exhaustivo, la disparidad entre el número de obras revisadas para cada compositor y el no haber podido acceder siempre a las ediciones más autorizadas. 
una o más secciones sin modulación ni inflexión alguna. A objeto de que esta muestra sea lo más representativa posible, he elegido dos piezas latinas -una misa y una lamentación para Semana Santa- y dos vernáculas -un villancico de Navidad y el himno de un trisagio a la Santísima Trinidad-.

El hecho de focalizar la atención en un aspecto particular conlleva, necesariamente, dejar de lado otros del conjunto. Sin embargo, esta limitación es propia de todo análisis musical. Como afirma Nattiez, "Nadie está obligado a dar cuenta de una obra en su totalidad y en todos sus aspectos, pues un análisis, sea de tipo exegético o semiológico, es siempre parcial". Así, el investigador no tiene más opción que definir sus prioridades, consciente de que ciertos aspectos "habrán quedado en la penumbra" (Nattiez 2011: 49). La otra cara de la moneda, sin embargo, es que un análisis intensivo de determinados elementos hace posible vislumbrar relaciones o aspectos que de otro modo pasarían inadvertidos y pueden modificar significativamente nuestra impresión del conjunto ${ }^{20}$. En términos simples, lo que se pierde en un sentido se gana en el otro.

Así mismo, el hecho de considerar aspectos formales no implica un desinterés por la función y el sentido de la música. Como afirma Treitler, el formalismo tradicional puede parecernos insatisfactorio por su concepción dogmática de la obra musical como un objeto autónomo y cerrado en sí mismo, pero esto no es razón suficiente para abandonar la creencia de que

una aproximación personal y provisoria a una expresión musical dada, sin relacionarla, por el momento, con algo más, es no solo una condición posible, sino necesaria para entenderla finalmente en sus conexiones más densas ${ }^{21}$.

De hecho, veremos cómo los rasgos estructurales que he agrupado en forma de tablas (ver Apéndices) nos llevan, inevitablemente, a abordar las relaciones entre música y texto.

Misa a 3

En la Catedral de Santiago, como en otras del orbe hispano, una de las principales obligaciones de la capilla y su maestro consistía, a fines del siglo XVIII, en acudir "todos los días de fiesta a la misa mayor". Así lo establecía un decreto de 1770 promulgado por el obispo Manuel de Alday. Además, en virtud de una capellanía fundada en 1634 por el obispo Francisco de Salcedo, la capilla debía asistir a la misa del Santísimo Sacramento que se celebraba cada jueves. Más adelante, en 1788, se estableció la obligación adicional de participar todos los miércoles del año en la misa mayor o "conventual" (cf. Andrés y Vera 2018: 468-470 y Apéndice 2). No sorprende, pues, que uno de los géneros más cultivados por Campderrós durante su estadía en Santiago fuese el ordinario de la misa.

Rara vez, sin embargo, musicalizó todas las secciones. La única versión íntegra de su autoría corresponde a una misa en re mayor en la que el "Agnus Dei" figura solo en las copias más tardías, lo que sugiere que se trata de una inclusión posterior ${ }^{22}$. Es probable, no obstante, que otro caso se halle en una "Misa a 4" en mi mayor que compuso en 1801. Si

20 Así lo afirma Agawu (2004: 270-271) en relación con el análisis musical, pero su afirmación coincide con el paradigma indiciario propuesto por Ginzburg (1994: 138-175) para la investigación histórica.

21 “... a provisional personal engagement with a musical utterance for the moment unrelated to anything else is not only a possible but a necessary condition of eventual understanding of it in its most dense connections". Citado por Hooper 2006: 89.

22 ACS, FM, carpeta 302. 
bien esta obra incluye solo el Kyrie y el Gloria, se conservan tres piezas sueltas, en la misma tonalidad, que probablemente fueron concebidas para completar el ciclo: un "Sanctus y Agnus Dei” atribuido al propio Campderrós y un Credo anónimo, pero copiado por su mano ${ }^{23}$. Considerando que la inclusión de estas secciones dependía del momento litúrgico -por ejemplo, en tiempos de Adviento y Cuaresma era frecuente ejecutar la misa sin Gloria ni Credo (Marín 2007: 739), mientras que durante el Tiempo Pascual las misas de feria se decían normalmente con Gloria, pero sin Credo (Irayzos 1777: 8)-24 parece probable que el compositor entendiese estas secciones como "módulos" flexibles que podían añadirse o quitarse según las necesidades de cada festividad.

La "Misa a 3" en do mayor (Tabla 1, No 23) está escrita para tres partes vocales -"primera voz", "segunda voz", bajo-y orquesta -dos violines, dos oboes, continuo y órgano-25. $\mathrm{Al}$ igual que otras misas de Campderrós, ${ }^{26}$ solo incluye el Kyrie y el Gloria, además de una breve introducción instrumental. Aunque la copia conservada fue realizada íntegramente por su mano ${ }^{27}$, parece haber agregado las dos partes para oboe en un momento posterior, ya que la portada no las menciona ${ }^{28}$.

En la Tabla 2 indico sus modulaciones e inflexiones, junto con otros hitos armónicos relevantes. Puede verse que Campderrós sí emplea funciones transitorias y procedimientos afines, como dominantes de la subdominante. Además, modula con cierta regularidad a las tonalidades vecinas -la dominante o la relativa, dependiendo del modo-. De hecho, en el Kyrie y el "Gratias agimus tibi" (cc. 120-140) se produce lo que Jan La Rue llamaba "tonalidad bifocal", esto es, una oscilación continua entre la tonalidad principal y su relativa (La Rue 2001: 283-294). Sin embargo, dos de sus secciones -el "Gloria in excelsis Deo" y el "Quoniam tu solus"- no presentan modulación ni inflexión alguna a otra tonalidad, situación impensable en el repertorio galante y clásico, como hemos visto en el apartado anterior, aun cuando se trate de misas breves.

Ahora bien, hay a lo menos tres pasajes que presentan una mayor actividad tonal. En el "Laudamus te", escrito en fa mayor, luego de una modulación a la dominante, hay una dominante secundaria de la nueva tonalidad (c. 91) que parece relacionarse con el sentido del texto. Como es sabido, esta sección del Gloria se inicia con cuatro expresiones consecutivas de alabanza: "Laudamus te, benedicimus te, adoramus te, glorificamus te". Debido a que la función transitoria y la modulación previa aparecen sobre la tercera de ellas, su función parece consistir en incrementar la tensión armónica, de modo que la última y más importante ("glorificamus te") vaya acompañada de una descarga de tensión -resolución en do mayor (c. 94) y vuelta a la tónica (c. 96) - con la consiguiente "liberación emocional", en términos meyerianos (cf. Meyer 1956: 28). Simultáneamente, Campderrós introduce un

23 ACS, FM, carpetas 175 y 254 para la misa; 168 para el Sanctus y Agnus Dei; y 169 para el Credo. Hay una copia adicional de la misa, pero en re mayor, en la carpeta 87.

24 El tiempo pascual era el período del año litúrgico que iba desde el domingo de Pascua de Resurrección hasta el de Pentecostés. El término feria correspondía a cualquier día de la semana a excepción del sábado y el domingo.

25 La obra se conserva en el ACS, FM, Carpeta 14. Una interpretación en vivo a cargo del grupo Capilla de Indias se encuentra disponible en YouTube, https://www.youtube.com/ watch?v=35m7JD7A_3o (consultada el 04-08-2019).

26 ACS, FM, Carpetas 257 ("Misa a 4" en mi bemol mayor); y 174, 172, 255, 256 ("Misa a tres voces" en re mayor).

27 A excepción de un duplicado del continuo, que se debe a un copista más tardío. De los copistas de la catedral de Santiago véase Vera 2013: 19-22.

28 Cf. Marchant 2006: 33, quien atribuye esta inclusión a José Antonio González, erróneamente a mi juicio. 
melisma sobre la palabra "glorificamus", apelando a una antigua convención de la ópera italiana, según esta, las palabras con una mayor carga afectiva daban lugar a pasajes de este tipo (cf. Marcello 1841: 10-11). Además, refuerza todo ello mediante el uso de semicorcheas en los violines y fusas en las voces.

El segundo pasaje se halla en el "Gratias agimus tibi" (c. 120) y consiste en una modulación a La menor por medio de un acorde de tercera disminuida, es decir, una sexta aumentada con séptima, pero en estado fundamental (ejemplo 1) ${ }^{29}$. Si incluso entre los "clásicos" este acorde es infrecuente (cf. no obstante Gauldin 2009: 472-476), su presencia en esta misa parece explicarse por el texto "Jesucristo unigénito" (Unigenite Jesu Christe). Se trata de la primera referencia a Cristo en el Gloria y encierra un significado teológico profundo, que alude a sus cualidades distintivas como hijo único del Padre ${ }^{30}$. De manera que Campderrós emplea la sonoridad más disonante sobre uno de los términos de mayor importancia teológica.

El tercer pasaje se halla en el propio "Gratias agimus tibi". Nuevamente reaparece el acorde de tercera disminuida de La menor, pero ahora sin séptima y en dos ocasiones consecutivas (cc. 137-139). En este caso, la áspera sonoridad se relaciona con la palabra peccata, ya que transgrede deliberadamente el modo más ortodoxo de tratar los acordes de sexta aumentada.

\section{Lamentación a solo}

Desde fines del siglo XVII, las "Reglas, consuetas, e instituciones consuetudinales" de la Catedral de Santiago establecían que debían cantarse las "Tinieblas" del miércoles, jueves y viernes santo (Carrasco 1691: 62). El "Oficio de Tinieblas" era, en efecto, el nombre que solía darse al servicio de maitines y laudes que incluía las Lamentaciones de Jeremías ${ }^{31}$. Así, un documento posterior, el "Plan de arreglo" para la capilla de música, prescribe explícitamente su asistencia a las "Lamentaciones, Christus y Miserere" que se cantaban en dichos días. Pese a ser tardío (1840), podemos asumir que refleja una práctica de larga data en la institución (cf. Andrés y Vera 2018: 489).

Examinaremos la tercera lamentación para el Jueves Santo (ver Tabla 1, № 2) en una versión que Campderrós escribió para bajo solo, clarinete, dos violines y continuo ${ }^{32}$. Es preciso señalar que todas las partes conservadas fueron copiadas por el compositor, incluso una de "Primera voz" que escribió posteriormente para ser cantada "en lugar de la del Bajo"33.

Como es sabido, el texto de las lamentaciones presenta varias elegías a la destrucción de Jerusalén a manos de los babilonios y atribuye esta desgracia a las infidelidades del pueblo de Judá (Olarte Martínez 1992: 82). Por esta razón, el teórico italiano Pietro Cerone afirmaba en su tratado de 1613:

29 Es importante señalar que el cifrado del órgano es original, por mano de Campderrós, e indica expresamente el fa natural.

30 Así lo indica la definición de "unigénito" en el Diccionario de Autoridades de la RAE: "Por antonomasia se entiende el Verbo Eterno, Hijo de Dios, que es y se llama el Unigénito del Padre". He consultado los diccionarios históricos de la RAE en el Nuevo Tesoro Lexicográfico de la Lengua Española (en adelante NTLLE), disponible en http://ntlle.rae.es/ntlle/SrvltGUIMenuNtlle?cmd=L ema\&sec=1.1.0.0.0 [acceso: 3 de diciembre de 2018].

31 Véase "Oficio de tinieblas", en Enciclopedia Católica, disponible en http://ec.aciprensa.com/ wiki/Oficio_de_tinieblas [acceso: 4 de agosto de 2019].

32 "Lamentación a solo [...] $3^{\text {ra }}$ para el Jueves Sto". ACS, FM, Carpeta 464.

33 Para este análisis he considerado únicamente la versión original para voz de bajo. 
En estas, más que en otras composiciones, se sirve el compositor de las disonancias, ligaduras, y de los pasos ásperos, para hacer su obra más llorosa y más lastimosa; como quiere el sentido de la letra, y como la representación del tiempo lo pide (citado por Olarte Martínez 1992: 100-101).

Como muestra la Tabla 3, la versión de Campderrós coincide con estas prescripciones, ya que emplea, reiteradamente, acordes disonantes y modulaciones con una función retórica. En la sección 1 hallamos una sexta italiana sobre las palabras "entre tinieblas" (in tenebras) ${ }^{34}$; en la sección 2, hay un acorde de $\mathrm{VII}_{7}$ de la dominante cuando el hablante afirma que su piel y su carne se han envejecido (Vetustam fecit pellem meam et carnem meam...), seguido por un cambio de modo cuando añade que se han roto sus huesos (contrivit ossa mea); en la sección 4, otro acorde de sexta italiana acompaña la referencia a "un lugar tenebroso" (In tenebrosis collocavit me); y en la sección 5 , el mismo tipo de acorde, seguido por una inflexión al modo menor (cc. 155-157), aparece sobre el texto "Me circunvaló por todos lados para que no escapase" (Circum adificavit adversum me, ut non egrediar) (ejemplo 2).

Ciertamente, la relación entre los acordes disonantes y el texto no siempre resulta tan clara, pues en la sección 5 (c. 151) y la siguiente (c. 176) una sexta alemana acompaña la palabra o letra Ghimel. Pero es posible que estas disonancias reflejen el carácter lúgubre de la pieza en su conjunto.

\section{"Amados pastores"}

La tercera pieza seleccionada es el villancico navideño "Amados pastores" (Tabla 1, $\mathrm{N}^{\circ}$ 3), escrito originalmente para tres voces, violines, órgano y bajo continuo ${ }^{35}$. Como es sabido, el villancico era una pieza con texto sacro, en lengua romance y con acompañamiento instrumental. A inicios del siglo XVII incluía normalmente un estribillo, seguido por unas coplas o estrofas, entre estas solía intercalarse la responsión o "respuesta de coplas" (una repetición parcial del estribillo). A fines de dicho siglo, el género comenzó a incrementar su número de secciones y a incluir recitativos y arias, lo que convirtió a algunos villancicos en verdaderas cantatas de carácter religioso ${ }^{36}$.

Sin alcanzar estas proporciones, "Amados pastores" excede la estructura clásica de estribillo-coplas, pues consta de tres secciones. La primera corresponde a lo que en ciertos villancicos se designa como pastorela, esto es, una pieza protagonizada por pastores y generalmente dedicada a la Navidad. Desde el punto de vista musical, las pastorelas se caracterizan por el uso de extensos pedales en el bajo que remedan el sonido de la gaita, así como por la métrica en octavos (6/8 en este caso), la predominancia de determinadas secuencias rítmicas (negra-corchea; corchea con punto-semicorchea-corchea), el tempo moderado y un carácter representativo o parateatral, todos rasgos presentes en esta sección (cf. Ramos 2007: 287-294) ${ }^{37}$.

La que sigue, en la tonalidad de la dominante y compás de 3/4, está escrita al modo de una "Bolera", como indica el original. Según una definición algo tardía, pero seguramente extrapolable a la época que nos ocupa, se trataba de un baile español que se ejecutaba en los teatros con "vestidos de majos" y en el que una o más parejas ejecutaban mudanzas al

34 Para la traducción me he basado en Torres Amat 1834: 165-166.

35 ACS, FM, Carpeta 1. Dichas partes son las que indica la portada y presentan la mano del compositor. La pieza incluye, además, dos partes de oboe anotadas por el copista 2 de la catedral (cf. Vera 2013: 19-22), pero parece tratarse de una inclusión posterior, ya que contribuye a "ensuciar" la sonoridad de la obra con disonancias que se tratan descuidadamente.

36 Para una visión panorámica del villancico, véase Knighton y Torrente 2007; y Torrente 2016.

37 Para el caso específico de "Amados pastores", cf. Feller 2017: 16, 19. 
"toque de seguidillas" 38 . El texto resulta coherente con esto último, pues Campderrós utiliza la métrica de la seguidilla, alternando versos heptasílabos y pentasílabos ("Grande alivio y descanso / paz y contento..."). Además, su estructura consiste en tres coplas seguidas por un estribillo, casi como si fuese una pieza independiente.

Para concluir, un breve coro a cuatro voces nos lleva de vuelta a la tonalidad principal de re mayor y al ambiente pastoril, pues reaparecen el compás en octavos (3/8) y el pedal de tónica -esto último en los compases intermedios, que los pastores cantan a dúo-.

Como muestra la Tabla 4, la sección inicial presenta una modulación a la dominante que se alcanza convencionalmente. Sin embargo, luego (cc. 31-39) la pieza modula bruscamente a si menor mediante su dominante séptima (ejemplo 3). Este movimiento hacia el sexto grado, poco frecuente entre los "clásicos" 39 , parece responder una vez más a las características del texto. Como suele ocurrir en las pastorelas, esta sección es dialógica y presenta la interacción de dos hablantes: el ángel que anuncia la buena nueva ("Amados pastores, queridos zagales, ¿cómo estáis tan quietos con tanto descanso, cuando por los valles todo es algazara...?"); y los pastores, que despiertan sobresaltados y piden explicaciones acerca de lo ocurrido ("Pues ¿qué ha sucedido? Cuéntanos despacio, para que sepamos lo que tú nos traes") ${ }^{40}$. Por tanto, la modulación a si menor indica no solo el paso de un hablante a otro, sino el cambio en el registro o lugar de enunciación de los personajes: mientras uno habla desde el mundo sobrenatural, los otros le responden desde el mundo terrenal, lo que explica que estén ligados a tonalidades contrastantes.

Esta interpretación puede explicar también la aparición anterior (cc. 19-20) de la dominante secundaria y dominante séptima de si menor, en lo que constituye una breve inflexión al sexto grado: posiblemente anticipa el despertar de los pastores, como si estos se revolcasen en su lecho, aún dormidos, pero ya inquietos por la llamada del Ángel.

Así, en la primera sección de este villancico los movimientos hacia el sexto grado -y no así la modulación a la dominante- se relacionan con el sentido del texto. Por el contrario, las secciones que siguen prácticamente no presentan modulaciones o inflexiones, a excepción de dos soles naturales en la segunda que, pese a ser notas de paso, pueden interpretarse como una breve inflexión hacia la subdominante.

\section{Himno del trisagio a solo}

La cuarta y última de las piezas escogidas presenta una mayor actividad tonal. Se trata de un trisagio en sol mayor (ver Tabla $1, \mathrm{~N}^{\circ} 30$ ) para voz sola, dos violines, dos flautas y continuo ${ }^{41}$. Según la definición de la Real Academia Española, el trisagio era un "Himno en honor de la santísima Trinidad que se recita o canta muy frecuentemente por los fieles cristianos". Esta definición está ausente del diccionario antes de $1832^{42}$, lo que sugiere que este género musical apareció tardíamente, quizá a fines del siglo XVIII.

La estructura de la obra es similar a la de numerosos trisagios cuyos textos fueron impresos en la época, particularmente por la orden Trinitaria (por ejemplo, Trisagio seráfico

38 Véase el diccionario de Castro y Rossi (1852), "Bolero o Boleras", en el NTLLE.

39 La brusca alternancia entre la tónica y el sexto grado parece haber sido utilizada por compositores como Schumann, justamente, para diferenciarse del estilo clásico (cf. Smith 2009: 47-86).

40 El episodio se describe en el Evangelio Según San Lucas (cf. Scío 1857: 55).

41 ACS, FM, carpeta 4. Tanto el título contenido en algunos encabezados ("trisagio a solo") como la caligrafía demuestran que las dos voces adicionales que hoy se conservan fueron añadidas en una época posterior, posiblemente por el maestro de capilla José Bernardo Alzedo.

42 Véase el NTLLE. Anteriormente solo se define como "El canto de los serafines, repetido tres veces el nombre Santo; y por extensión se dice de cualquier festividad repetida por tres días” $(1803,859)$. 
1820: 23-25). Luego de un himno inicial de alabanza a la Santísima Trinidad, se canta el "Santo" con su doxología ("Gloria al padre..."). Sigue otro texto de alabanza a dicho misterio y una oración, que en la versión de Campderrós está dirigida a la Virgen María. La pieza concluye con un breve estribillo ("Dios uno y trino a quien tanto[s] / arcángeles, querubines...") seguido por los "gozos", esto es, varias estrofas o coplas que glosan el motivo de la celebración y entre las que se intercala el estribillo inicial.

A causa de la extensión de la obra, me limitaré a analizar el himno inicial. Como muestra la Tabla 5, las modulaciones e inflexiones más llamativas (cc. 27, 63 y 73) coinciden con la aparición de calderones que suspenden el curso de la música. El hecho de que estos pasajes sean tres constituye una evidente alusión al misterio de la Santísima Trinidad. Pero lo más interesante es que las detenciones se producen en partes del texto conceptualmente complejas, que señalan sus fundamentos -“... el sol ardiente y así o luz perenne unida” (Dios y lo eterno) ${ }^{43}$, "en la mansión infinita” (el paraíso) - o elementos constitutivos -"al Padre, al Hijo y a Ti [el Espíritu Santo]"-. Por esta razón, las inflexiones o modulaciones parecen expresar la complejidad del misterio, mientras los calderones representan la reflexión sosegada que esta amerita. En este sentido, su uso es similar al de la Misa en do mayor en las palabras Unigenite Jesu Christe.

La última de estas detenciones, luego de una progresión por quintas, tiene lugar en la dominante de mi menor (c. 73). Pero en lugar de resolver en la nueva tónica (ver ejemplo 4), como podría esperarse, Campderrós introduce súbitamente el acorde de sol mayor y da inicio a una recapitulación, en la que el canto alaba efusivamente al Espíritu Santo (“iEspíritu que das vida!”). Esta ruptura de la expectativa (cf. Meyer 1956) y regocijo posterior podrían indicar que el misterio de la Santísima Trinidad no se puede comprender racionalmente, pero sí gozarse afectivamente.

\section{Síntesis}

En términos generales, uno de los rasgos que se desprenden de las obras analizadas es que las modulaciones o inflexiones a tonalidades vecinas -la dominante en el modo mayor y la relativa en el modo menor- no parecen tener una relación específica con algún aspecto extramusical. Por el contrario, los movimientos hacia otras tonalidades y los acordes disonantes cumplen casi siempre una función retórica, es decir, buscan expresar musicalmente el significado negativo de alguna palabra o frase, su importancia y complejidad, o su sentido dramático.

Pero si la modulación desempeña en dichas obras una función expresiva, no parece tener una función estructural -no, al menos, al nivel que lo hace en la obra de los "clásicos"-. Como se explica detalladamente en trabajos como los de Caplin (1998) o Hepokoski y Darcy $(2006)^{44}$, en la música europea de fines del siglo XVIII el establecimiento de una tonalidad secundaria (normalmente una de las tonalidades vecinas ya señaladas) contribuye a dar forma a la pieza, porque produce la tensión armónica precisa para que la posterior vuelta a la tonalidad principal sea percibida como una necesidad. Esto es así desde las formas binarias más simples (por ejemplo, un minueto) ${ }^{45}$ hasta la forma sonata y sus variantes, en las que la tonalidad secundaria da lugar a una sección contrastante -el segundo tema-. Si bien las excursiones hacia otras tonalidades presentan una mayor libertad, hay igualmente

43 Interpreto unitariamente los dos calderones consecutivos que aquí aparecen.

44 Para el repertorio anterior del siglo XVIII cf. Taruskin 2010: 120-122, 177-198, 399-426; y, para el estilo galante, Radice 1999.

45 Para un ejemplo en estilo galante, cf. Gjerdingen 2007: 73-76. 
algunas tendencias que prevalecen, como el hecho de que aparezcan preferentemente después de la tonalidad secundaria, o que la subdominante suela alcanzarse hacia el final de la obra ${ }^{46}$. Desde luego, esta estructura -y sus innumerables variantes- desempeña también una función expresiva y puede incluso entenderse como un "drama" (Cf. entre otros Cook 1994: 14-16), pero esto depende, al menos en parte, de las tensiones y relaciones armónicas que la constituyen (i.e., de su forma) (cf. al respecto Hepokoski y Darcy 2006: 658).

Las cuatro obras de Campderrós que hemos analizado exhiben alguna similitud con estos principios, ya que, en más de una ocasión, la primera tonalidad a la que se modula es la dominante del modo mayor o la relativa del modo menor ${ }^{47}$. Además, dos secciones presentan una inflexión hacia la subdominante cerca del cierre ${ }^{48}$.

Sin embargo, incluso en estos casos la secuencia tonal que dibujan las modulaciones posteriores es diferente. Por ejemplo, el "Gratias agimus tibi" de la "Misa a 3" modula a la dominante, pero luego lo hace a la relativa menor en dos ocasiones (I-V-I-VI-I-VI-I). Así mismo, la sección inicial de la "Lamentación a solo" modula dos veces a la relativa mayor, volviendo en ambas a la tonalidad principal (I-III-I-III-I). En el primer caso, la dominante no tiene el peso que alcanza en las obras clásicas. En el segundo, la relativa mayor no produce la tensión y el contraste ya comentados, debido a que retorna rápidamente a la tonalidad principal. La secuencia tonal pareciera incluso ser azarosa -se modula dos veces a la relativa menor como podría haberse modulado una o tres- o al menos no responder a un molde preestablecido.

A lo anterior se añade la inclusión, ya comentada, de secciones sin movimiento alguno a otras tonalidades, hecho que dificulta entender el lenguaje musical de Campderrós como un reflejo del estilo galante. La conclusión es que, sin perjuicio de la recepción que el repertorio galante y clásico tuvo en España y la América colonial ${ }^{49}$, la obra del músico catalán no responde del todo a los principios que lo caracterizan. Por lo mismo, parece probable que responda a otros principios o convenciones.

\section{UNA MIRADA A LA TEORÍA MUSICAL ESPAÑOLA DEL SIGLO XVIII}

En el ámbito hispano, hay que esperar hasta 1762 para encontrar una primera formulación teórica respecto de la modulación. Esta se halla en el tratado del padre Antonio Soler (1762), quien distingue, como es sabido, una modulación "lenta" -que pasa gradualmente por varios "términos"-, y otra "agitada" -que pasa bruscamente "del término remoto al propio"-. Además, afirma la existencia de solo dos modos -mayor y menor-, lo que sitúa su pensamiento en el marco de la tonalidad moderna (cf. Capdepón 2002: 1126) ${ }^{50}$. A partir de este momento se multiplicarán los teóricos españoles que tratan el tema, como

46 Incluso, a veces, da inicio a la recapitulación de la forma sonata (Cf. Hepokoski y Darcy 2006: 697-709 -paginación del libro electrónico-). Asimismo, ya en las obras galantes se observan algunos de estos rasgos, como la expansión de la segunda parte en la forma binaria. Además, si bien los primeros compositores "galantes" utilizan la modulación de una forma más libre que los clásicos, progresivamente comienzan a elaborar "planes tonales” a gran escala (Radice 1999: 621, 643).

47 Secciones 2, 3-2 y 3-3 de la "Misa a 3"; 1 y 2 de la "Lamentación a solo"; y 1 de "Amados pastores".

48 Secciones 3-3 y 3-5 de la "Misa a 3"; y 6 de la "Lamentación a solo".

49 Los trabajos son demasiados como para listarlos aquí. Véanse, entre otros, Stevenson 1982; Merino 1986; Miranda 1997 y Marín López 2018.

50 Algunos teóricos españoles anteriores aluden a la existencia de solo dos modos, pero sin que esto implique un abandono del sistema modal (véase García Gallardo 2011: 136; y García Gallardo y Murphy 2016: 87-88). 
prueban, entre otros, Del origen y reglas de la música de Eximeno $(1774)^{51}$, Dialectos músicos de Francisco de Santa María (1778) ${ }^{52}$, el "Compendio teórico y práctico de la modulación" de José Lidón (ca. 1780) ${ }^{53}$ y el "Tratado completo de composición fundamental" de Pedro Aranaz y Vides y Francisco Olivares (1807) ${ }^{54}$.

En principio, la modulación parece estar ausente de los tratados anteriores ${ }^{55}$, pero al menos uno de ellos la aborda de manera indirecta: me refiero a la Escuela música de fray Pablo Nassarre, que incluye serias advertencias contra la creciente tendencia de los compositores españoles a "salirse de las especies del tono" a causa de la influencia de los italianos. Por ejemplo, en la segunda parte de su libro, Nassarre cuestiona la presencia de un Mi bemol en una pieza escrita en el octavo tono natural:

Yaunque semejante postura la hacen con frecuencia, no es por reparar ningún inconveniente, sino es por poner modos de cantar extraordinarios, valiéndose los maestros españoles de ejemplares extranjeros y especialmente italianos.

No es mi ánimo el impugnarlo en este lugar, pero no dejaré de decir la impropiedad que tiene: y es el introducir especies de otros tonos, que son impropias del que es la obra. La tercera menor sobre Cesolfaut [Do] es propia del primer tono punto bajo y de algunos otros accidentales, pero no del octavo tono natural. Pues si se puede componer con variedad sin salirse de las especies de cada tono, ¿qué necesidad hay de valerse de las del ajeno? (Nassarre 1723: 76).

Más adelante, vuelve a censurar esta tendencia, de un modo aún más enfático:

Y aunque no ha sido nuestra nación la más defectuosa en esto, se va introduciendo este contagio, originado de la música italiana, que no dejan signo donde no usen de bemoles y sustenidos, sin guardar orden en los diapasones; materia que se hace insufrible a los oídos artizados (Ibídem, p. 370).

El contagio, sin embargo, se hacía extensivo al empleo indiscriminado de disonancias, sin más pretexto que "variar sus cantinelas" y "dar gusto" (Nassarre 1724: prólogo al lector, sin paginación). Para el teórico aragonés, esto no correspondía a la manera española de escribir música, que era "más ceñida a las reglas" (Nassarre 1723: 246).

Debemos advertir, para no incurrir en el problema de la falsa "traducción" señalado por Zaldívar (Nassarre 2006: 274), que Nassarre no está pensando en la tonalidad moderna, como hará Soler, sino en los ocho tonos polifónicos o eclesiásticos que tradicionalmente se empleaban en España. Como es sabido, estos derivaban de los tonos salmódicos y fueron expuestos por vez primera en el tratado de Lorente (1672), aunque su empleo pueda rastrearse en fuentes anteriores (García Gallardo y Murphy 2016: 79-86; Illari 2013). Cada tono se distinguía por un conjunto de rasgos formales que incluían la escala o diapasón, la armadura y las llaves utilizadas, que podían ser naturales o transpositoras. Además, tenían una nota principal, llamada final, y otra secundaria, llamada mediación. En la tabla 6 sintetizo las características esenciales del sistema según Nassarre, similares, aunque no idénticas, a

51 Publicado originalmente en Italia (1774) y posteriormente traducido al castellano (1796) (Eximeno 1796, especialmente el tomo II, capítulo V).

52 Contra lo que se ha afirmado (cf. López Ruiz 2017: 296), este autor sí aborda la modulación en el sentido que nos ocupa, pues afirma que "cuando se salga del tono, y se vuelva, se debe procurar que sea perfecta y dulce la modulación”, e incluye al final del libro ejemplos de "Modulaciones", "para alivio de los que empiezan a trabajar" (Santa María 1778: 163-164, 208 y “Suplemento”, pp. 290 y siguientes).

53 Conservado en dos ejemplares, uno en la Catedral de Santiago de Compostela (AM-LE 33) y otro en la Biblioteca de Catalunya (M. 132). Cf. López Ruiz 2017: 250.

54 Biblioteca Nacional de España, M 1244, pp. 86-97.

55 Así lo afirma Lidón en su tratado, citado por López Ruiz 2017: 253. 
las de Lorente (cf. Nassarre 2006: 194; Robledo 2016: 597; García Gallardo y Murphy 2016: 77). Puede verse que cada tono tiene al menos dos formas de anotarse, según se empleen llaves naturales o transpositoras. Además, los tonos 4, 7 y 8 pueden concluir en la mediación y el tercero admite dos diapasones diferentes (desde la o mi).

La recomendación de Nassarre es que los compositores españoles procuren hacer las cadencias o cláusulas sobre las notas más propias de cada tono. Estas son, principalmente, la finaly la mediación (Nassarre 1724: 312; Nassarre 1723: 371). Además, admite las cláusulas sobre otros grados de la escala, exceptuando el si cuando la armadura no lleva accidentes y el mi cuando lleva si bemol (es decir, excluye únicamente la nota que produce la quinta disminuida al hacer cláusula sobre ella). Así, por ejemplo, las notas más apropiadas para "clausular" en el primer tono natural son re (final) y la (mediación), pero también es posible hacerlo sobre mi, fa, sol y do (Nassarre 1724: 432-434; Nassarre 1723: 367-368) ${ }^{56}$. Aun así, el teórico advierte que estas cuatro cláusulas adicionales no se deben usar con tanta frecuencia "porque no están en proporciones sonoras todas con la del final, como está la de la mediación" (Nassarre 1724: 432). En otras palabras, y el punto es importante porque puede inducir a confusión, no es que el compositor pueda clausular indistintamente en las seis notas señaladas: la final y la mediación tienen clara preferencia, mientras las otras deben emplearse de manera más esporádica, pues lo contrario equivaldría a "salirse del tono" (Nassarre 1723: 369).

Ahora bien, Nassarre admite el empleo de otras cláusulas con ciertas finalidades, a saber: cuando es necesario agregar accidentes para modificar algunos intervalos o cantar ciertas partes con mayor "suavidad"; para variar la sonoridad en obras extensas, compuestas por varias secciones, cada una escrita en un tono diferente, siempre que el paso de uno a otro no "violente" al oído (Nassarre 1723: 371); y, lo que más nos interesa, para "expresar con más propiedad el afecto de la letra", siempre que se haga sin que se sienta

diformidad [sic] ni disonancia, faltando a la buena melodía, llamando la atención con las antecedentes cláusulas a la que se ha de hacer fuera de tono; y al tiempo de volver a las que fueren propias de él ha de ser también con suavidad y sin violencia (Nassarre 1723: 368-369) ${ }^{57}$.

Según el autor, la necesidad de expresar el sentido de la letra sería tan importante en la música vernácula como en la litúrgica:

[En ocasiones] se ponen algunas posturas con alguna diferencia de como dejo escrito; mayormente cuando es necesario expresarlo con algunas falsas [disonancias] sobre algunas palabras dolorosas provocativas a lástima u otras semejantes que quieren la música muy grave y devota. $\mathrm{Y}$ aunque en la letra vulgar se ofrece muchas componer tales períodos, pero debe el compositor atender más a la de latín, por ofrecerse con frecuencia el poner en música palabras muy misteriosas de las muchas que hay en el oficio divino y en el santo sacrificio de la misa... (Ibidem, p. 313. Cf. P. 300).

56 Su planteamiento, en este punto, es un poco más restrictivo que el de Lorente (1672: 565566), pues este último afirma que "las cláusulas que dejamos puestas en el final, y supuestas en la mediación, son las principales" y que en las demás notas de la escala "se podrá clausar [sic] a voluntad del compositor...".

57 En sus Fragmentos músicos (1683), afirma además que los "grandes maestros" suelen hacer cláusulas fuera del tono, pero "por la larga experiencia que tienen de componer, aunque se salgan del Tono, lo saben hacer con tal primor, que no se escandalice el oído..." (citado por Sanz Gómez 2017: 499). 
Así, el sentido del texto puede conllevar no solo la aparición de cláusulas ajenas al tono, sino también el empleo de disonancias inusuales ${ }^{58}$, tanto en el caso de palabras "dolorosas" como "misteriosas" o de difícil comprensión.

Las citas anteriores me parecen pertinentes por varias razones. Primero, aunque el autor se refiera a cláusulas y no a modulaciones propiamente tales, sus palabras responden a la creciente influencia del repertorio italiano practicado en torno a 1700, que se caracterizaba, justamente, por modular con frecuencia de una tonalidad a otra. Se trata, pues, de la reacción de un músico español ante una práctica diferente y de origen foráneo ${ }^{59}$.

Segundo, los preceptos tradicionales continuaron vigentes en España con posterioridad a la introducción de la tonalidad moderna. Francisco de Santa María, por ejemplo, reconocía en sus Dialectos músicos de 1778 la existencia de solo dos modos, pero afirmaba que en España continuaban usándose los ocho tonos eclesiásticos porque la mayor parte de la música se hacía para la Iglesia (Santa María 1778: 170-171; cf. García Gallardo 2011: 137, 142; y García Gallardo y Murphy 2016: 87). Así mismo, a partir de 1770, autores como Fernando Ferandiere y Juan Antonio de Vargas y Guzmán mantendrían los ocho tonos como marco de referencia, pero comenzarían a aplicarles armaduras modernas -por ejemplo, Ferandiere apunta el segundo tono con dos bemoles en la armadura, como si fuese la tonalidad de sol menor- (García Gallardo 2011: 143-147).

Tercero, de los autores tradicionales, Nassarre es el más influyente y citado por los teóricos españoles del siglo XVIII, superando incluso a Cerone y Lorente (Anzaldúa 2009: 14). Roel del Río, por ejemplo, sin mencionarlo de forma explícita, reproduce sus preceptos en su tratado de 1748, cuando critica a los compositores modernos que

por ignorancia o por presumpción [sic], de tal suerte abusan de las reglas más constantes del arte que, sin prevención la menor, ponen pasajes y aun cláusulas sumamente distantes y estrañas al diapasón o escala de dichas composiciones, con que destruyen la armonía que piden y dificultan determinar aun de qué tono sea... (Roel 1748: 18).

El propio Soler recurre reiteradamente a Nassarre para fundamentar algunas de sus afirmaciones. Más aún, lo considera, junto con Lorente, un autor "de nuestro tiempo" (Nassarre 2006: 47-48).

Finalmente, Nassarre es citado en el tratado de Bernardo Comes y Puig, impreso en Barcelona en 1739 (Anzaldúa 2009: 14) ${ }^{60}$, y en la "Guía para principiantes" (ca. 1720) de Pedro Rabassa, músico nacido y formado musicalmente en dicha ciudad (Isusi Fagoaga 1997: 403). Además, su Escuela música estaba presente, a fines del siglo XVIII, en las bibliotecas del colegio jesuita de Lima ${ }^{61}$ y el convento de San Francisco de Santiago de Chile (Vera 2005: 29). De modo que, aun sin estar seguros de dónde se formó Campderrós como músico, la obra del teórico aragonés era conocida en todas las ciudades donde su presencia ha sido documentada.

58 Planteamiento expresado antes por Lorente (1672: 285, 377, 541), quien admite el uso de quintas aumentadas y otras disonancias acentuadas "cuando la letra lo pidiere".

59 Acerca de la influencia del estilo italiano en la música española desde finales del siglo XVII, véase Torrente 2000; Torrente 2014; y Domínguez 2016.

60 De hecho, el título del tratado de Comes (Fragmentos músicos) es idéntico al del primer libro de Nassarre.

61 Archivo Nacional de Chile, Fondo Jesuitas de América, vol. 405, Inventario del Colegio de San Pablo, fol. 312. 


\section{CONCLUSIONES}

En sus trabajos ya citados, cuya relevancia ha quedado clara en las páginas anteriores, García Gallardo y Murphy sugieren que la persistencia del sistema tradicional no tuvo implicaciones para la composición, porque consistía, simplemente, en homologar las tonalidades mayores y menores con los ocho tonos "naturales" o sus transposiciones (García Gallardo y Murphy 2016: 88). Pienso que el caso de Campderrós sugiere justamente lo contrario, esto es, que algunos de los procedimientos que emplea en su obra pueden explicarse por la persistencia de los preceptos acuñados por Nassarre, siguiendo la línea que fuera insinuada hace algunos años por Velásquez Cantín ${ }^{62}$. Después de todo, parece poco probable que un tratado como la Escuela música fuese aún tan influyente entre los músicos españoles de fines del siglo XVIII, sin que esto tuviese la menor repercusión en su forma de componer.

Más allá de posibles correspondencias entre las tonalidades que Campderrós emplea y algún tono eclesiástico particular ${ }^{63}$, las obras analizadas muestran coincidencias con Nassarre en el hecho de que las modulaciones hacia tonalidades vecinas -la dominante o relativa mayor, según el caso- parecen realizarse sin más pretensión que variar la sonoridad y el curso de la música, mientras que los movimientos hacia otras tonalidades se emplean siempre -o casi siempre- para "expresar con más propiedad el afecto de la letra" y suelen ir acompañados por acordes disonantes, principalmente disminuidos, de séptima o de sexta aumentada ${ }^{64}$. Esto explicaría que su orden de aparición sea variable y que la música pueda ir y volver a una misma tonalidad más de una vez, pues ambas cosas dependerían, fundamentalmente, del sentido y las características del texto.

También resulta concordante con su preceptiva el hecho de no modular en ciertas secciones. Recordemos que el teórico aragonés criticaba a los italianos por sus modulaciones excesivas y recomendaba a los españoles no seguir su ejemplo ${ }^{65}$, ya que era posible "componer con variedad sin salirse de las especies de cada tono". Por lo demás, el hecho confirma que la modulación no tiene para Campderrós un rol tan esencial como para los compositores galantes y, especialmente, clásicos.

Una última coincidencia con Nassarre, más específica, se da en la "Misa a 3" y el "Trisagio a solo", cuando Campderrós emplea disonancias o modulaciones inesperadas para representar la importancia del término "unigénito" y la complejidad del misterio de la Santísima Trinidad. Se trata, justamente, de palabras "misteriosas de las muchas que hay en el oficio divino y en el santo sacrificio de la misa...".

Desde luego, haría falta analizar un mayor número de casos y géneros ${ }^{66}$ para realizar afirmaciones más concluyentes. Aun así, pienso que, en su conjunto, la evidencia presentada hace probable que lo que Urrutia consideró un simple defecto técnico refleje más bien la

62 Véase la Introducción.

63 Por ejemplo, podría plantearse que, en la sección 3-3 de la misa, la tonalidad de do mayor corresponde a un quinto tono y su dominante a la mediación.

64 Resulta interesante que Francesc Queralt (1740-1825), compositor nacido en Cataluña y activo en Barcelona desde su juventud, utilice también los acordes de sexta aumentada con fines retóricos en algunos de sus oratorios (véase Daufí 2001: 263). Aun así, parece más probable que se trate de un rasgo compartido por los músicos españoles de la época, que de una marca de estilo propia de los autores catalanes. Agradezco a Aurèlia Pessarrodona el haber llamado mi atención acerca del trabajo de Daufí.

65 Así como iba a hacer Roel del Río en 1748, según ya hemos visto.

66 Por ejemplo, la Tabla 1 (Nos. 25, sección 1 y 30, sección 3, entre otros) muestra que en los recitativos las modulaciones e inflexiones se incrementan, por tratarse de un género esencialmente modulante. 
confluencia, en el mundo hispano de fines del siglo XVIII, entre una preceptiva tradicional, aún anclada en la modalidad, y una práctica moderna de carácter tonal ${ }^{67}$.

Para finalizar, quisiera comentar brevemente las posibles proyecciones de este trabajo. Resulta interesante que diversos especialistas hayan apuntado la presencia de "defectos" similares en otros compositores activos en la América colonial, no vinculados directamente con Campderrós. Drew Davies afirma que los compositores novohispanos del siglo XVIII se diferencian de los italianos por su uso "inconsistente" y "no convencional" de las modulaciones (Davies 2006: 271-272, 486-487); y Bernardo Illari sostiene que la obra "americana" de Domenico Zipoli se diferencia de la que compuso en Italia por consistir en "piezas más simples", "cuya expresión tiende a encuadrarse dentro de una tipología menos amplia" y sin "una estructura de largo alcance que sea sonoramente efectiva" (Illari 1994: 124, 140) ${ }^{68}$.

Otras investigaciones han apuntado características afines en compositores españoles que nunca visitaron América, pero cuya obra, en parte, se ha conservado allí. Olga SánchezKisielewska considera al lenguaje de José de Nebra representativo de una variante española del estilo napolitano galante, que se caracterizaría, entre otras cosas, por una discordancia entre las modulaciones y los esquemas melódico-armónicos utilizados (Olga SánchezKisielewska 2015: 40 ${ }^{69}$; y Gladys Zamora afirma que las obras de Tomás de Ochando son igualmente tributarias de dicho estilo, pero presentan una menor cantidad de modulaciones, especialmente hacia tonalidades menores (Zamora 2017) ${ }^{70}$.

¿Estamos hablando de un modo de componer hispano -o colonial- al que los compositores foráneos -como Zipoli- solían adaptarse cuando llegaban a América? Y, en caso de ser así, ¿pueden, algunas de sus características, explicarse por la influencia de la teoría musical española de comienzos del siglo XVIII? Ambas preguntas quedan abiertas a futuras investigaciones pertinentes al tema. Aun así, pienso que el tipo de aproximación propuesto en este trabajo puede resultar útil para comenzar a responderlas.

\section{BIBLIOGRAFÍA}

Agawu, Kofi

2004 "How We Got out of Analysis, and How to Get Back in Again". Music Analysis, 23/ii-iii, pp. 267-286. DOI: 10.1111/j.0262-5245.2004.00204.x

Andrés Fernández, David y Alejandro Vera

2018 "De la polifonía al canto llano. Reconstruyendo las prácticas músico-litúrgicas en la Catedral de Santiago de Chile (1721-1840)". Revista de Musicología, 41/2, pp. 459-508. DOI: $10.2307 / 26554762$

Anzaldúa, Luis Carlos

2009 "Los conceptos contrapuntísticos de Pablo Nassarre", Nassarre, 25: 13-37.

Bach, Carl Philipp Emanuel

1771 Geistliche Oden und Lieder. Berlín: George Ludewig Winter.

67 Sobre la dialéctica entre tradición e innovación en la música española de la época véase, entre otros, Leza 2014: 125-438. Es importante señalar que también puede interpretarse como un resabio tradicional el uso ya señalado de la "tonalidad bifocal" en algunas secciones, pues se trata de un recurso empleado desde fines del siglo XV y presente en patrones acórdicos como la Romanesca y las Folías.

68 Cf. Illari 2011: 167-169, donde refuta su hipótesis anterior acerca de una posible conversión espiritual del compositor y relaciona este cambio con la influencia del estilo galante.

69 Para una descripción detallada de los esquemas galantes más frecuentes, ver Gjerdingen 2007.

70 Agradezco a la autora el haberme enviado su texto antes de ser publicado. 
Cabrera, VAleska

2010 "Persistencia de la colonia en la música de la Catedral de Santiago de Chile", Cuadernos de Música Iberoamericana, 19, pp. 27-61.

Capdepón, Paulino

2002 "Soler y Ramos, Antonio", Diccionario de la Música Española e Hispanoamericana. Editado por Emilio Casares. Vol. 9. Madrid: SGAE, p. 1126.

Caplin, William E.

1998 Classical Form. A Theory of Formal Functions for the Instrumental Music of Haydn, Mozart, and Beethoven. Oxford: Oxford University Press.

Carrasco, Bernardo

1691 Synodo Diocesana [1688]. Lima: Imprenta de Joseph de Contreras y Alvarado.

Claro Valdés, Samuel

1974a Catálogo del archivo musical de la catedral de Santiago de Chile. Santiago: Universidad de Chile, Instituto de Extensión Musical.

1977a "José de Campderrós (1742-1812): de mercader catalán a maestro de capilla en Santiago de Chile”, Anuario Musical, 30, pp. 123-134.

1977b “Artes musicales y coreográficas”, Cultura chilena. Santiago: Universidad de Chile, pp. 241-270.

1979 "Música catedralicia en Santiago durante el siglo pasado". Revista Musical Chilena, XXXIII/148, pp. 7-36.

Claro Valdés, Samuel (ED.)

1974b Antología de la música colonial en América del Sur. Santiago: Universidad de Chile.

Claro Valdés, Samuel, y Jorge Urrutia Blondel

1973 Historia de la música en Chile. Santiago: Orbe.

CoOK, Nicholas

1994 A Guide to Musical Analysis. Oxford: Oxford University Press.

DAUfí, XAVIER

2001 "Estudi dels oratoris de Francesc Queralt (1740-1825): fonaments de la història de l'oratori a Catalunya al segle XVIII". Tesis doctoral, Universitat Autònoma de Barcelona.

DAvies, Drew EDWARD

2006 "The Italianized Frontier: Music at Durango Cathedral, Español Culture, and the Aesthetics of Devotion in Eighteenth-Century New Spain”. Tesis doctoral, The University of Chicago.

Domínguez, José María

2016 "Un fin de siglo renovador", Historia de la música en España e Hispanoamérica. Editado por Álvaro Torrente. Vol. 3, La música en el siglo XVII. Madrid: Fondo de Cultura Económica, pp. 705-757.

Estenssoro, Juan Carlos

1989 Música y sociedad coloniales. Lima 1680-1830. Lima: Colmillo Blanco.

Eximeno, Antonio

1796 Del origen y reglas de la música. Francisco Antonio Gutiérrez (traductor). Madrid: Imprenta Real.

Feller, Paul

2017 "Pesebre en música: los signos de la escena del Nacimiento en los villancicos de Navidad catedralicios en Santiago de Chile (c. 1780-c. 1808)". Tesis de licenciatura, Pontificia Universidad Católica de Chile.

García Gallardo, Cristóbal

2011 "Viejos conceptos para nuevas músicas: la llegada de la tonalidad moderna a los teóricos españoles”, MAR, Música de Andalucía en la Red, I/1, pp. 135-147. 
García Gallardo, Cristóbal y Paul Murphy

2016 “These are the Tones Commonly Used': The Tonos de Canto de Órgano in Spanish Baroque Music Theory", Eighteenth-Century Music, XIII/1 (marzo), pp. 73-93. DOI: 10.1017/ S1478570615000433

GAuldin, Robert

2009 La práctica armónica en la música tonal. Madrid: Akal.

Gembero Ustárroz, María

2007 "Migraciones de músicos entre España y América (siglos XVI-XVIII): estudio preliminar”, $L a$ música y el Atlántico. Relaciones musicales entre España y Latinoamérica. María Gembero Ustárroz y Emilio Ros-Fábregas (editores). Granada: Universidad de Granada, pp. 17-58.

Ginzburg, Carlo

1994 Mitos, emblemas e indicios. Barcelona: Gedisa.

GJERDingen, RoberT O.

2007 Music in the Galant Style. Nueva York: Oxford University Press.

Heinlein, Federico

1971 "Crítica Musical. Concierto en la Catedral". El Mercurio (12 de septiembre), p. 51.

Hepokoski, James y WarRen Darcy

2006 Elements of Sonata Theory. Norms, Types and Deformations in the Late-Eighteenth-Century Sonata. Oxford: Oxford University Press.

Hettrick, Jane Schatkin

1986 "A Thematic Catalogue of Sacred Works by Antonio Salieri: An Uncatalogued Holograph of the Composer in the Archive of the Vienna Hofkapelle", Fontes Artis Musicae, XXXIII/3 (julio-septiembre), pp. 226-235.

HoOper, Giles

2006 The Discourse of Musicology. Aldershot, UK: Ashgate.

ILLARI, BERNARDO

1994 "La personalidad de Zipoli a la luz de su obra americana", Domenico Zipoli. Itinerari iberoamericani della musica italiana nel settecento (Atti del Convegno Internazionale, Prato, 30 settembre - 2 ottobre 1988). Mila de Santis (editora). Florencia: Leo S. Olschki editore, pp. 111-176.

2011 Domenico Zipoli: para una genealogía de la música clásica latinoamericana. La Habana: Fondo Editorial Casa de las Américas.

2013 “Son modos? Tonos y salmodia en Andrés Lorente”, Analizar, interpretar, hacer música: de las Cantigas de Santa María a la organología. Escritos in memoriam Gerardo V. Huseby, Melanie Plesch (editora). Buenos Aires: Gourmet Musical, pp. 289-326.

IRAYZOS, FERMín dE

1777 Instrucción acerca de las rúbricas generales del misal. Madrid: Imprenta de Pedro Marín.

IsUSi FAgOAGA, RosA

1997 "Pedro Rabassa en la teoría musical del siglo XVIII: algunos aspectos sobre instrumentos y voces según su Guía para principiantes”, Revista de Musicología, XX/1 (enero-diciembre), pp. $401-416$.

Knighton, Tess y Álvaro Torrente (EDS.)

2007 Devotional Music in the Iberian World, 1450-1800. The Villancico and Related Genres. Aldershot, Hampshire: Ashgate.

LA RUE, JAN

2001 "Bifocal Tonality: An Explanation for Ambiguous Baroque Cadences", Journal of Musicology, XVIII/2 (primavera), pp. 283-294 (reimpresión del texto original de 1957).

Leza, José Máximo (ED.)

2014 Historia de la música en España e Hispanoamérica, vol. 4, La música en el siglo XVIII. Madrid: Fondo de Cultura Económica. 
López Ruiz, Luis

2017 "El compositor José Lidón (1748-1827): obra teórica y análisis de su música litúrgica”. Tesis doctoral, Universidad Complutense de Madrid.

LORENTE, ANDRÉS

1672 El porqué de la música. Alcalá de Henares: Nicolás de Xamares.

Marcello, Benedetto

1841 Il teatro di música alla moda. Florencia: Guglielmo Piatti (edición original de 1720).

Marchant, Guillermo

2006 "Acercándonos al repertorio del archivo musical de la Catedral de Santiago de Chile en la primera mitad del siglo XIX”, Revista Musical Chilena, LV/206 (julio-diciembre), pp. 28-48.

MARÍN López, JAVIER

2007 "Música y músicos entre dos mundos: la Catedral de México y sus libros de polifonía (siglos XVI-XVIII)”. Tesis doctoral, Universidad de Granada.

2018 "Mecenazgo musical e identidad aristocrática en el México ilustrado: Miguel de Berrio y Zaldívar, Conde de San Mateo de Valparaíso (1716-1779)”, Latin American Music Review, XXXIX/1 (primavera-verano), pp. 1-29. DOI: 10.7560/LAMR39101

Merino, Luis

1986 "An 18th-century source of Haydn's music in Chile”, Bericht uber den Internationalen Joseph Haydn Kongress, Wien, Hofburg, 1982. Eva Badura-Skoda (editora). Munich: G. Henle Verlag, pp. 504-510.

MEYER, LEONARD

1956 Emotion and Meaning in Music. Chicago y Londres: The University of Chicago Press.

MiRANDA, RicARDo

1997 "Reflexiones sobre el clasicismo en México (1770-1840)", Heterofonía, 116-117, pp. 39-50.

NASSARre, Pablo

1723 Segunda parte de la Escuela música. Zaragoza: Herederos de Manuel Román.

1724 Escuela música según la práctica moderna. Zaragoza: Herederos de Diego de Larumbe.

2006 Fragmentos músicos, Álvaro Zaldívar Gracia (editor). Vol. II, Anexo. Estudio general introductorio de la vida y obra de Nassarre. Zaragoza: Institución Fernando el Católico.

NATtiez, JEAN-Jacques

2011 "De la semiología general a la semiología musical. El modelo tripartito ejemplificado en $L a$ Cathédrale engloutie de Debussy", Reflexiones sobre semiología musical, Susana González Aktories y Gonzalo Camacho Díaz (editores). Ciudad de México: UNAM, pp. 14-51.

Olarte Martínez, Matilde

1992 "La forma musical de la lamentación”. Anuario Musical, 67, pp. 81-101.

Pereira Salas, Eugenio

1941 Los origenes del arte musical en Chile. Santiago: Universidad de Chile.

Radice, Mark A.

1999 "The Nature of the 'Style Galant': Evidence from the Repertoire”. The Musical Quarterly, LXXXIII/4, pp. 607-647. DOI: $10.1093 / \mathrm{mq} / 83.4 .607$

Robledo, Luis

2016 "Pensamiento musical y teoría de la música", Historia de la música en España e Hispanoamérica. Vol. 3, La música en el siglo XVII, Álvaro Torrente (editor). Madrid: Fondo de Cultura Económica de España, pp. 531-617.

Roel del Río, ANTonio

1748 Institución harmónica o doctrina musical theorica y practica que trata del canto llano y de órgano. Madrid: Herederos de la Viuda de Juan García Infanzón. 
SÁNCHEZ-KisielewSKA, OlgA

2015 "Claves para el Análisis del Italianismo en la Música Hispana: Esquemas Galantes y Figuras Retóricas en las Misas de Jerusalem y Nebra”. Diagonal, I/1, pp. 28-53. DOI: 10.5070/ D81128584

SAnta María, Francisco de

1778 Dialectos músicos. Madrid: Joaquín Ibarra.

SANz Gómez, Lucía

2017 "Introducción al estudio filológico de un diálogo musical: Fragmentos músicos de Pablo Nassarre", Studia Aurea, XI/11, pp. 481-509. DOI: 10.5565/rev/studiaaurea.244

Scío de San Miguel, Felipe

1857 El Nuevo Testamento traducido al español de la Vulgata Latina. Londres: Spottiswoode y Compañía.

SMith, Peter H.

2009 "Harmonies Heard from Afar: Tonal Pairing, Formal Design, and Cyclical Integration in Schumann's A-minor Violin Sonata, op. 105”, Theory and Practice, 34, pp. 47-86.

SOLER, ANTONio

1762 Llave de la modulación y antigüedades de la música. Madrid: Joaquín Ibarra.

STEVEnSON, Robert

1982 "Los contactos de Haydn con el Mundo Ibérico", Revista Musical Chilena, XXXVI/157 (enero-junio), pp. 3-39.

TARUSKIN, RICHARD

$2010 \quad$ Music in the Seventeenth and Eighteenth Centuries. Oxford: Oxford University Press.

TORRente, Álvaro

2000 "Las secciones italianizantes de los villancicos de la Capilla Real, 1700-1740", La música en España en el siglo XVIII, Malcolm Boyd y Juan José Carreras (editores). Cambridge: Cambridge University Press, pp. 87-94.

2014 "La modernización/italianización de la música sacra”, Historia de la música en España e Hispanoamérica, vol. 4, La música en el siglo XVIII, José Máximo Leza (editor). Madrid: Fondo de Cultura Económica, pp. 125-156.

2016 "El villancico religioso", Historia de la música en España e Hispanoamérica, vol. 3, La música en el siglo XVII, Álvaro Torrente (editor). Madrid: Fondo de Cultura Económica de España, pp. $433-530$.

Torres Amat, Félix

1834 La Sagrada Biblia nuevamente traducida de la vulgata latina al español, segunda edición. Madrid: Imprenta de D. Miguel de Burgos.

TRISAGIO SERÁFICO

1820 Trisagio seráfico para venerar a la Santísima Augustísima Trinidad y alcanzar de su piedad inmensos beneficios. Cervera: Imprenta de José Casanovas.

URrutia Blondel, Jorge

1927 "La obra sinfónica de Beethoven y algunos aspectos de orquestación". Marsyas, I/1 (marzo), pp. 21-25.

1971 “Doña Isidora Zegers 1803-1869”, Revista Musical Chilena, XXV/113-114 (enero-junio), pp. 3-17.

Velásquez Cantín, Rebeca

2001 "José de Campderrós, maestro de capilla en la Catedral de Santiago de Chile en las postrimerías del siglo XVIII". Tesis de máster, Universidad de Chile.

2003 José de Campderrós. Músico colonial en Santiago de Chile. Valparaíso: Ediciones Puntángeles. 
Vera, Alejandro

2005 "A propósito de la recepción de música y músicos extranjeros en el Chile colonial", Cuadernos de Música Iberoamericana, 10, pp. 7-33.

2010a "Coro de cisnes, cantos de sirenas: una aproximación a la música en los monasterios del Chile colonial”, Revista Musical Chilena, LXIV/213 (enero-junio), pp. 26-43.

2013 "El fondo de música de la catedral de Santiago: redescubriendo un antiguo corpus musical a partir de su re-catalogación”, Neuma, VI/2, pp. 10-27.

ZAMORA, GLADYS

2017 "Más cerca de Nebra que de Nápoles: la misa en Re mayor de Tomás Ochando y las variantes nacionales del estilo galante". Ponencia presentada en el V Coloquio de Musicología de Morelia y II Coloquio de Edición de Textos Antiguos Celebración y sonoridad en Hispanoamérica (siglos XVI-XIX), Morelia (México).

\section{Grabaciones}

Rosas, Fernando (Dir.)

1972 Coro y orquesta de la Universidad Católica de Chile, Misa en Sol Mayor de José Campderrós [edición discográfica]. Santiago de Chile: Astral, SVB 104. 


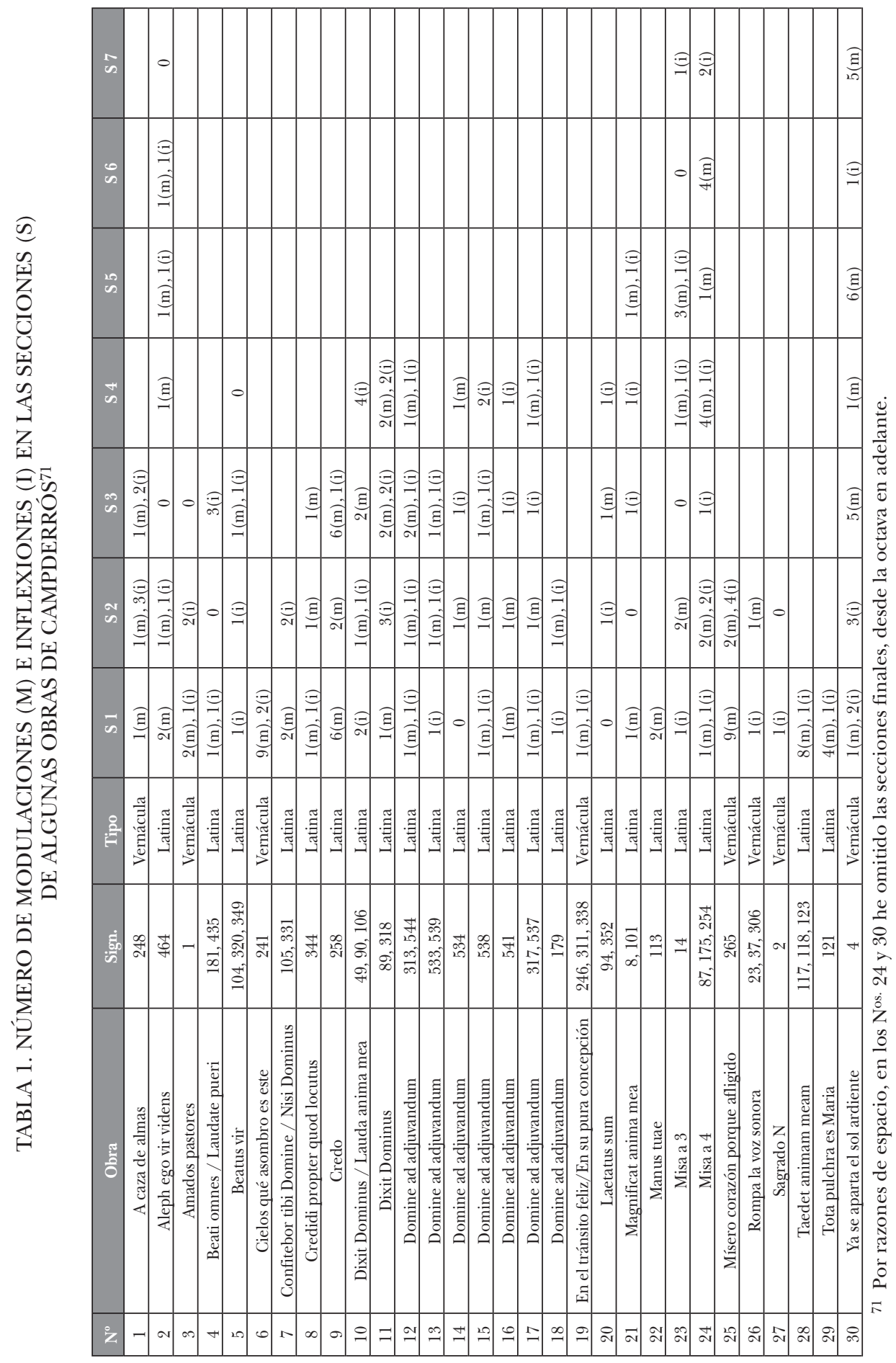


TABLA 2: MODULACIONES, INFLEXIONES Y OTROS HITOS ARMÓNICOS EN LA “MISA A 3" DE CAMPDERRÓS (ACS, FM, CARPETA 14)

\begin{tabular}{|c|c|c|c|}
\hline Sección & Subsección & Tonalidad & Observaciones \\
\hline 1. Intro. & Íd. & Do mayor & c. 10, inflexión a la dominante. \\
\hline 2. Kirie & Íd. & La menor & $\begin{array}{l}\text { Oscila entre la tonalidad principal y su } \\
\text { relativa. }\end{array}$ \\
\hline \multirow[t]{5}{*}{ 3. Gloria } & $\begin{array}{l}\text { 3-1. Gloria in excelsis } \\
\text { Deo }\end{array}$ & Do mayor & $\begin{array}{c}\text { Sin modulación ni inflexión hacia otra } \\
\text { tonalidad. }\end{array}$ \\
\hline & 3-2. Laudamus te & Fa mayor & $\begin{array}{l}\text { c. } 89 \text {, modulación a la dominante. } \\
\text { c. } 91 \text {, acorde de re mayor en primera } \\
\text { inversión (dominante secundaria de do } \\
\text { mayor). } \\
\text { c. } 96 \text {, retorno a fa mayor. }\end{array}$ \\
\hline & 3-3. Gratias agimus tibi & Do mayor & $\begin{array}{c}\text { cc. 112-116, modulación a la dominante. } \\
\text { c. } 117 \text {, retorno a do mayor. } \\
\text { cc. } 120-127 \text {, modulación a la relativa, } \\
\text { previa aparición de un acorde de tercera } \\
\text { disminuida. } \\
\text { c. } 128 \text {, retorno a do mayor. } \\
\text { c. } 134 \text {, nueva modulación a la relativa. } \\
\text { cc. } 137-139 \text {, aparecen dos acordes de } \\
\text { tercera disminuida. } \\
\text { c. } 149 \text {, retorno a do mayor. } \\
\text { c. } 153 \text {, acorde de dominante de la } \\
\text { subdominante. }\end{array}$ \\
\hline & $\begin{array}{l}\text { 3-4. Quoniam tu solus } \\
\text { sanctus }\end{array}$ & Sol mayor & $\begin{array}{c}\text { Sin modulación ni inflexión hacia otra } \\
\text { tonalidad. }\end{array}$ \\
\hline & $\begin{array}{l}\text { 3-5. Cum Sancto } \\
\text { Spiritu-Amen }\end{array}$ & Do mayor & $\begin{array}{l}\text { c. } 185 \text {, acorde de dominante de la } \\
\text { subdominante. }\end{array}$ \\
\hline
\end{tabular}


TABLA 3: MODULACIONES, INFLEXIONES Y OTROS HITOS ARMÓNICOS EN LA “LAMENTACIÓN A SOLO” DE CAMPDERRÓS (ACS, FM, CARPETA 464)

\begin{tabular}{|c|c|c|}
\hline Sección & Tonalidad & Observaciones \\
\hline $\begin{array}{l}\text { 1. Aleph. Ego vir } \\
\text { videns }\end{array}$ & La menor & $\begin{array}{l}\text { C. 9. Modulación a do mayor. } \\
\text { C. 19. Vuelta a la tonalidad principal. } \\
\text { C. } 43 \text {. Modulación a do mayor. } \\
\text { c. } 47 \text {. Vuelta a la tonalidad principal. } \\
\text { c. } 62 \text {. Acorde de sexta italiana. }\end{array}$ \\
\hline $\begin{array}{l}\text { 2. Beth. Vetustam } \\
\text { fecit pellem meam }\end{array}$ & Do mayor & $\begin{array}{l}\text { c. } 104 \text {. VII7 de la dominante en tercera inversión. } \\
\text { c. } 106 \text { y siguientes. Cambio de modo a do menor. }\end{array}$ \\
\hline $\begin{array}{l}\text { 3. Beth. Edificavit in } \\
\text { gyro meo }\end{array}$ & $\begin{array}{l}\text { Mi bemol } \\
\text { mayor }\end{array}$ & Sin modulación ni inflexión hacia otra tonalidad. \\
\hline $\begin{array}{c}\text { 4. Beth. In } \\
\text { tenebrosis collocavit } \\
\text { me }\end{array}$ & $\begin{array}{l}\text { Si bemol } \\
\text { mayor }\end{array}$ & $\begin{array}{l}\text { cc. 131-132. Modulación a sol menor y detención } \\
\text { sobre su dominante. } \\
\text { cc. } 137-138 \text {. Acorde de sexta italiana en dicha } \\
\text { tonalidad y detención sobre su dominante. } \\
\text { c. } 139 \text {. Vuelta a la tonalidad principal. }\end{array}$ \\
\hline $\begin{array}{l}\text { 5. Ghimel. Circum } \\
\text { ædificavit adversum } \\
\text { me }\end{array}$ & Fa mayor & $\begin{array}{l}\text { c. 151. Gesto inicial similar al de la sección anterior } \\
\text { (cc. 131-132), con la diferencia de que ahora hay un } \\
\text { acorde de sexta alemana en la nueva tonalidad } \\
\text { (re menor). } \\
\text { c. } 153 \text {. Vuelta a la tonalidad principal. } \\
\text { c. } 155 \text {. Acorde de sexta italiana. } \\
\text { c. } 157 \text {. Inflexión a fa menor, similar a la sección } 2 \text {, } \\
\text { c. } 106 .\end{array}$ \\
\hline $\begin{array}{l}\text { 6. Ghimel. Sed et } \\
\text { cum clamavero }\end{array}$ & Do mayor & $\begin{array}{l}\text { c. 168. Modulación a la menor. } \\
\text { c. 176. Sexta alemana en la nueva tonalidad. En } \\
\text { principio, estaría en estado fundamental, por llevar el } \\
\text { re sostenido en la voz del bajo (a menos que el bajo } \\
\text { continuo fuese tocado también por un contrabajo u } \\
\text { órgano, en cuyo caso sonaría también en la octava } \\
\text { interior y el acorde se oiría en primera inversión). } \\
\text { c. 178. Vuelta a do mayor. } \\
\text { c. } 182 \text {. Inflexión a la subdominante. }\end{array}$ \\
\hline $\begin{array}{l}\text { 7. Jerusalem } \\
\text { convertere }\end{array}$ & La menor & Sin modulación. \\
\hline
\end{tabular}


TABLA 4: MODULACIONES, INFLEXIONES Y OTROS HITOS ARMÓNICOS EN EL VILLANCICO “AMADOS PASTORES” DE CAMPDERRÓS (ACS, FM, CARPETA 1)

\begin{tabular}{|c|c|c|}
\hline Sección & Tonalidad & Observaciones \\
\hline $\begin{array}{l}\text { 1. Amados } \\
\text { pastores }\end{array}$ & Re mayor & $\begin{array}{l}\text { - C. 11, modulación a la dominante. } \\
\text { - C. 15, retorno a la tonalidad principal. } \\
\text { - Cc. 19-20, breve inflexión a si menor. } \\
\text { - C. 21, retorno a la tonalidad principal. } \\
\text { - C. } 31-39 \text {, aparición repentina del acorde } \\
\text { de dominante séptima de si menor, en estado } \\
\text { fundamental, con la consiguiente modulación a dicha } \\
\text { tonalidad. } \\
\text { - Cc. 40-44, retorno a re mayor y fin de la sección (esta } \\
\text { se canta tres veces, cada una con textos diferentes). }\end{array}$ \\
\hline $\begin{array}{l}\text { 2. Grande alivio y } \\
\text { descanso (bolera } \\
\text { a dúo) }\end{array}$ & La mayor & - Cc. 1 y 24, brevísimas inflexiones a la subdominante. \\
\hline $\begin{array}{l}\text { 3. Vamos } \\
\text { cantando pastores }\end{array}$ & Re mayor & Sin modulación ni inflexión hacia otra tonalidad. \\
\hline
\end{tabular}

\section{TABLA 5: MODULACIONES, INFLEXIONES Y OTROS HITOS ARMÓNICOS EN EL HIMNO INICIAL DEL TRISAGIO EN SOL MAYOR DE CAMPDERRÓS (ACS, FM, CARPETA 4)}

\begin{tabular}{|c|c|c|}
\hline Sección & Tonalidad & Observaciones \\
\hline $\begin{array}{c}\text { 1. Ya se aparta el } \\
\text { sol ardiente }\end{array}$ & Sol mayor & $\begin{array}{c}\text { - Cc. 3 y 13, breve inflexión a la subdominante. } \\
\text { - C. 27, inflexión a la menor; melisma en la voz entre } \\
\text { dos calderones consecutivos y rápido retorno a la } \\
\text { tonalidad principal (cc. 28-29). }\end{array}$ \\
& $\begin{array}{c}\text { - C. 63, inflexión a la dominante, bajo un calderón, } \\
\text { seguida por una aparición repentina de la dominante } \\
\text { de la menor (c. 64), que da pie a una progresión por } \\
\text { quintas descendentes (cc. 64-72). } \\
\text { - C. 73, fin de la progresión anterior por medio de una } \\
\text { cadencia suspensiva sobre la dominante de mi menor, } \\
\text { bajo un calderón. }\end{array}$ \\
\hline
\end{tabular}


TABLA 6: TONOS POLIFÓNICOS SEGÚN NASSARRE

(1724): 308-313

\begin{tabular}{|c|c|c|c|c|}
\hline Tono & Armadura & Tipo de llaves & Final & Mediación \\
\hline 1 & Con si bemol & Transpositoras & Sol & $\operatorname{Re}$ \\
\hline 1 & Sin bemol & Naturales & $\operatorname{Re}$ & $\mathrm{La}$ \\
\hline 2 & Con si bemol & Naturales & Sol & Si bemol \\
\hline 3 & Sin bemol & Transpositoras & $\mathrm{La}$ & Do \\
\hline 3 & Sin bemol & Transpositoras & Mi & Do \\
\hline 4 & Sin bemol & Naturales & Mi (o la) & $\mathrm{La}$ \\
\hline 5 & Con si bemol & Transpositoras & $\mathrm{Fa}$ & Do \\
\hline 5 & Sin bemol & Naturales & Do & Sol \\
\hline 6 & Con si bemol & Naturales & $\mathrm{Fa}$ & $\mathrm{La}$ \\
\hline 7 & Sin bemol & Transpositoras & La (o re) & $\operatorname{Re}$ \\
\hline 8 & Sin bemol & Transpositoras & Sol (o do) & Do \\
\hline 8 & Sin bemol & Naturales & Sol & Do \\
\hline
\end{tabular}




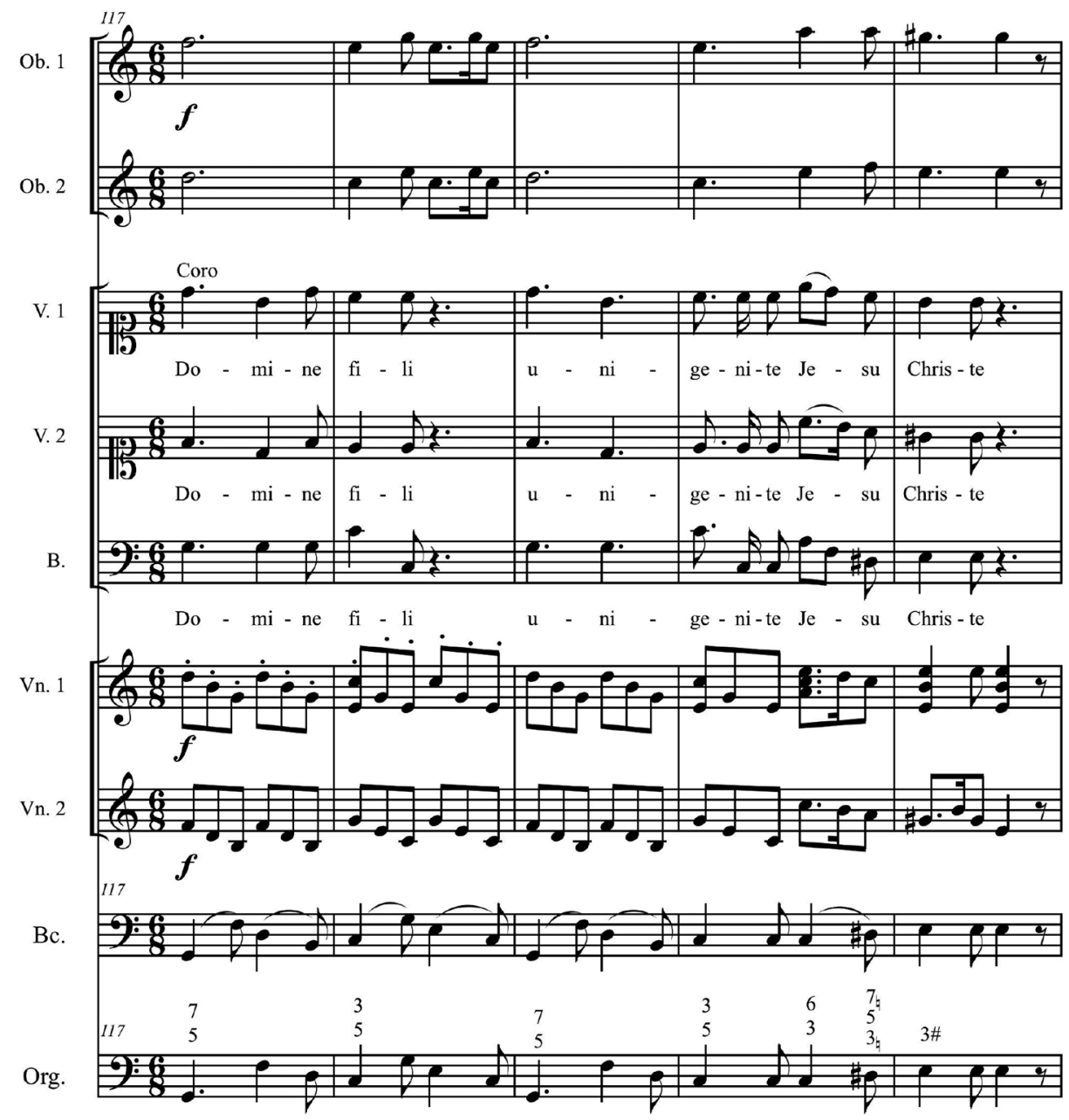

Ejemplo 1: fragmento de la "Misa a 3" de Campderrós (ACS, FM, Carpeta 14) 


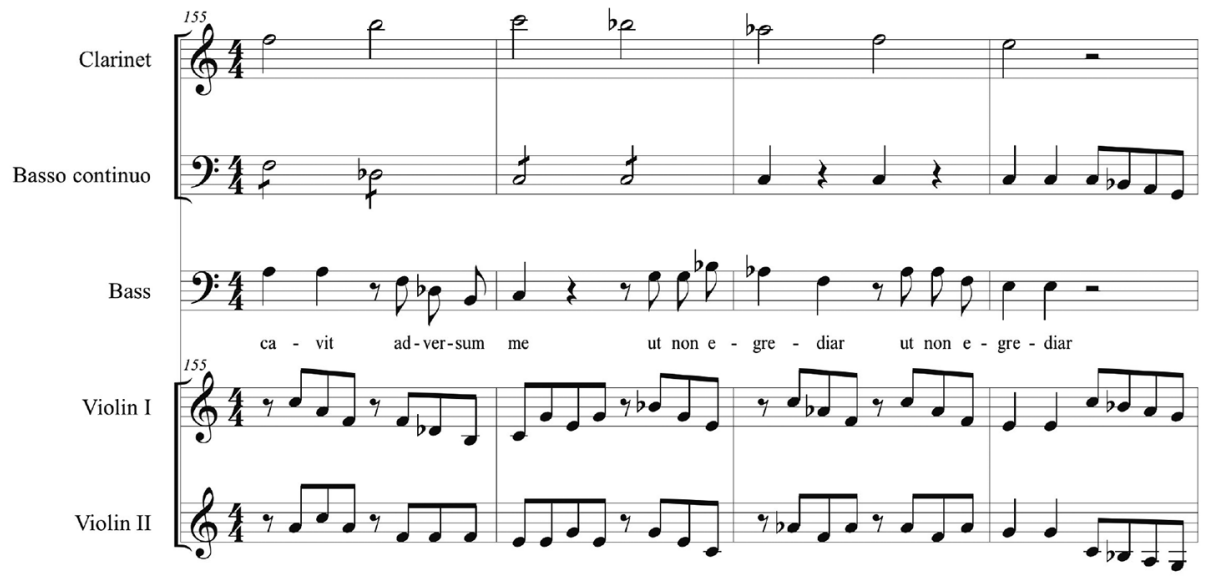

Ejemplo 2: fragmento de la "Lamentación a solo" de Campderrós (ACS, FM, Carpeta 464) 


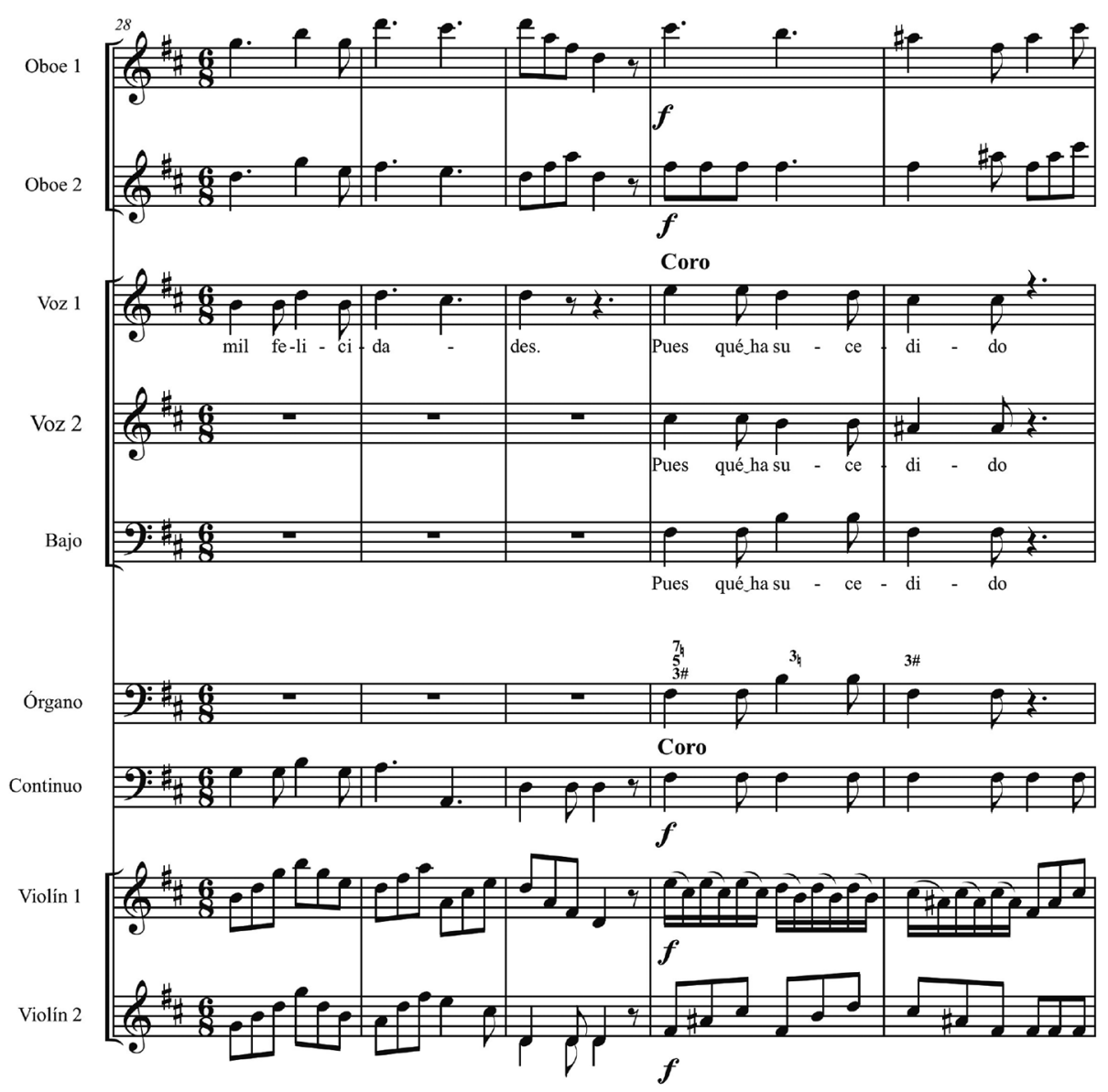

Ejemplo 3: fragmento del villancico "Amados pastores" de Campderrós (ACS, FM, Carpeta 1) 

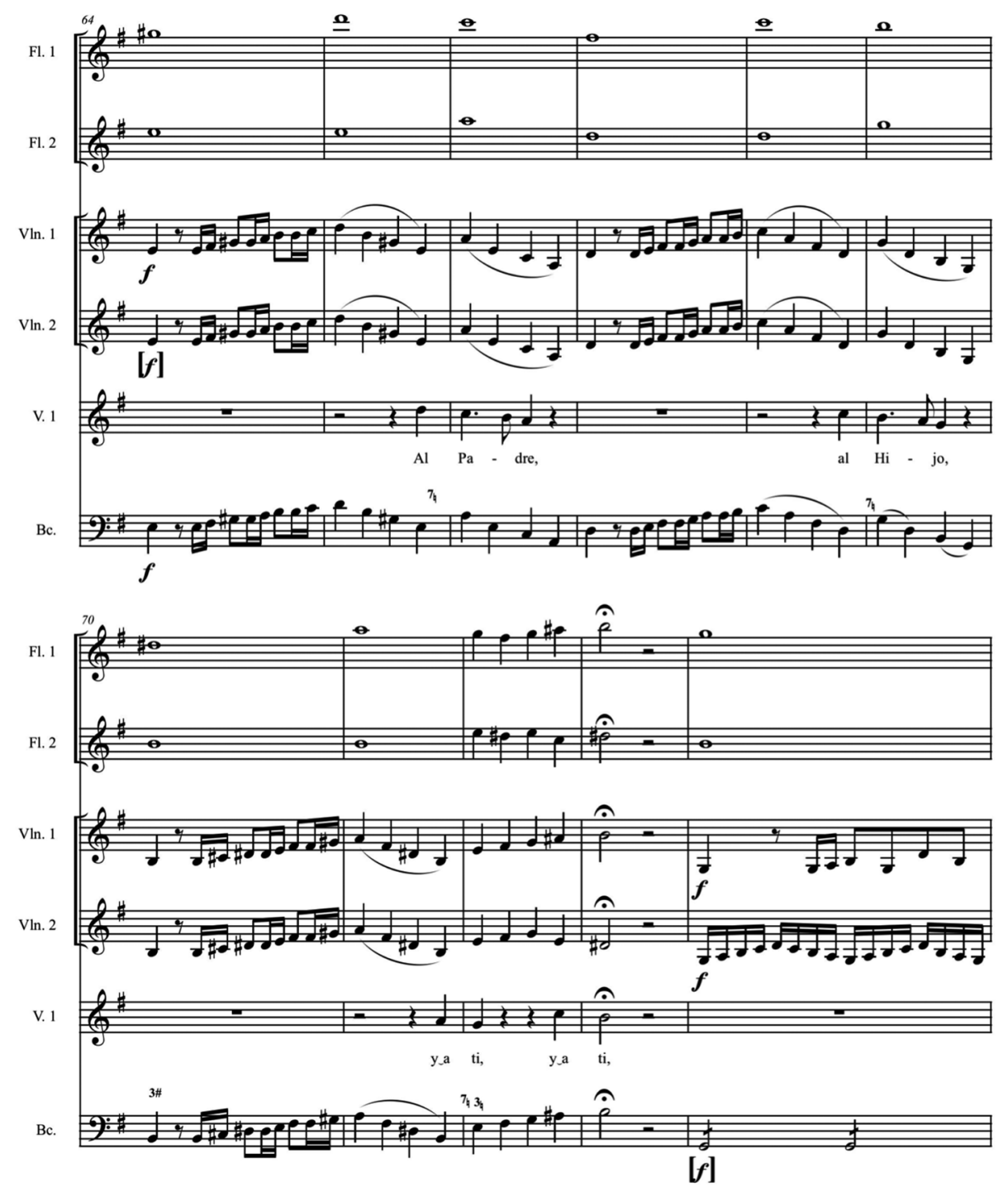

Ejemplo 4: fragmento del himno inicial del Trisagio en sol mayor de Campderrós (ACS, FM, Carpeta 4) 